NISTIR 8012

\title{
Standards Related to Prognostics and Health Management (PHM) for Manufacturing
}

\author{
Gregory W. Vogl \\ Brian A. Weiss \\ M. Alkan Donmez
}

http://dx.doi.org/10.6028/NIST.IR.8012

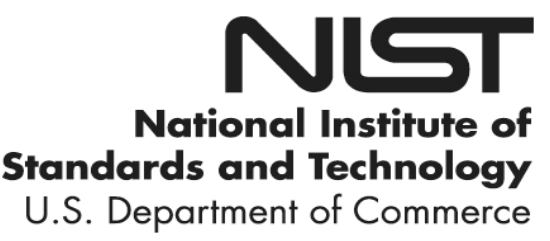


NISTIR 8012

\title{
Standards Related to Prognostics and Health Management (PHM) for Manufacturing
}

\author{
Gregory W. Vogl \\ Brian A. Weiss \\ M. Alkan Donmez \\ Intelligent Systems Division \\ Engineering Laboratory
}

This publication is available free of charge from: http://dx.doi.org/10.6028/NIST.IR.8012

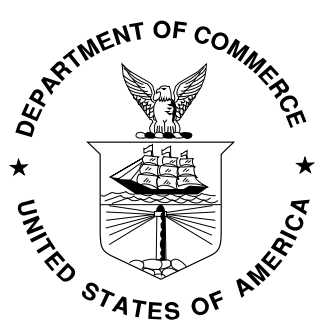

U.S. Department of Commerce Penny Pritzker, Secretary

National Institute of Standards and Technology Willie May, Acting Under Secretary of Commerce for Standards and Technology and Director 


\begin{abstract}
Prognostics and health management (PHM) technologies reduce burdensome maintenance tasks of products or processes through diagnostic and prognostic activities. These activities provide actionable information that enable intelligent decision-making for improved performance, safety, reliability, and maintainability. However, standards for PHM system development, data collection and analysis techniques, data management, system training, and software interoperability appear to be partly lacking. The National Institute of Standards and Technology ${ }^{1}$ (NIST) conducted a survey of PHM-related standards to determine the industries and needs addressed by such standards, the extent of these standards, and any similarities as well as potential gaps among the documents. Standards from various national and international organizations are summarized, including those from the Air Transport Association (ATA), the International Electrotechnical Commission (IEC), the International Organization for Standardization (ISO), the Society of Automotive Engineers (SAE), and the United States Army (US Army). Finally, recommendations are offered for the development of future PHM-related standards.
\end{abstract}

Keywords: diagnostics; health management; maintenance; manufacturing; monitoring; PHM; prognostics; standards

\footnotetext{
${ }^{1}$ Certain commercial equipment, instruments, or materials are identified in this document in order to adequately describe the implementation of the methodology. Such identification does not imply recommendation or endorsement by the National Institute of Standards and Technology, nor does it imply that the materials or equipment identified are necessarily the best available for the purpose.
} 


\section{Introduction}

\subsection{Prognostics and Health Management (PHM) Basics}

Prognostics and health management (PHM) systems and technologies enable maintenance action on products and processes based on need, determined by the current system condition via diagnostic analyses or the expected future condition through prognostic methods. PHM techniques are in contrast to the use of schedules where maintenance is conducted on specific time limits [1]. PHM aims to reduce burdensome maintenance tasks while increasing the availability, safety, and cost effectiveness for the products and processes to which it is applied. Therefore, PHM is enabled through data collection, diagnostics, and prognostics as well as usage monitoring.

PHM is a diverse, interdisciplinary field with evolving needs that is applicable to numerous domains, such as manufacturing, automotive, and aerospace industries [2]. PHM is a broad concept that includes prognostics, diagnostics, and condition-based monitoring. Specifically, PHM covers maintenance, logistics, and mission planning from both preventative and reactive approaches to monitor, schedule, and optimize asset management. The goal of PHM is to extend useful life, reduce unplanned maintenance events, and optimize availability and sustainment while reducing lifecycle costs of either products or processes. Specific PHM technologies are aimed at providing decision support; the output from a PHM system is actionable information that supports decision-making for improved performance, safety, reliability, and maintainability of the monitored product or process.

Figure 1 shows a flowchart of the general process of PHM system development. PHM system development begins with cost and dependability analyses to determine the components to monitor. The data management system is then initialized for collection, processing, visualization, and archiving of the maintenance data. Once the measurement techniques are established, the diagnostic and prognostic approaches are developed and tested to ensure that the desired goals are achieved. Finally, personnel are trained during the iterative process of system validation and verification before final system deployment. 


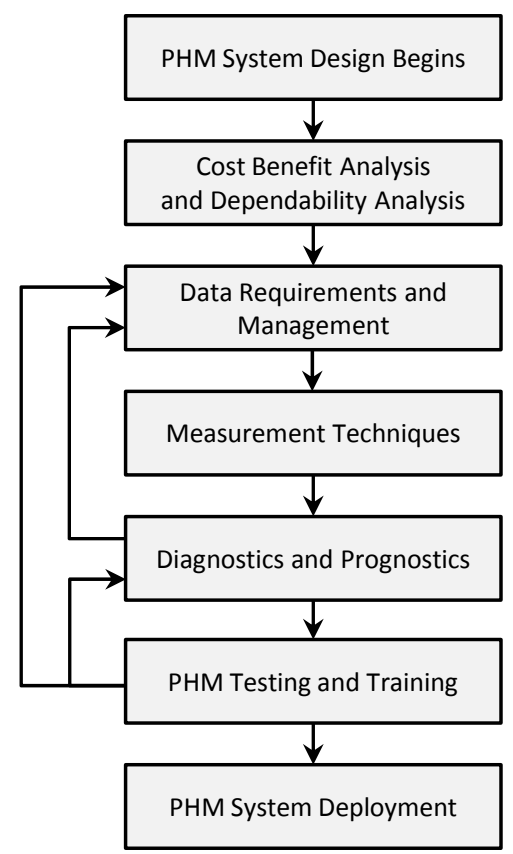

Figure 1. General PHM system development process.

\subsection{PHM Needs and Challenges}

PHM is dependent on data collection and processing for maintenance-related components or subsystems, so standards about data acquisition and processing are needed to influence the requirements for PHM systems development [1]. Standards for PHM are needed to address the lack of standardized terms, the lack of visibility, uniformity, and consistency of the PHM methods and tools, the need for compatibility and interoperability of PHM technology, and the needs for guidance in the practical use and development of PHM techniques [3].

Another goal of PHM is the comprehensive tracking of the performance and operational history of specific components; that is, components with serial numbers. The U.S. Army desires the capability of such a PHM system, but current obstacles include the lack of quality control, data management, software interoperability, and systematic serialization. These data-centric capabilities will enable the collection, transmission, storage, processing, and visibility of data within and among PHM systems [1].

Kalgren et al. [4] presented terminology and associated definitions for PHM that have been used for mechanical, structural, and propulsion technologies in an attempt to address this situation and to aid in the general application of PHM. For example, PHM was defined along with concepts like the gray-scale health index (from 0 to 1) for diagnostics and remaining useful life (RUL) for prognostics [4].

The creation of PHM systems is still difficult due to the inter-related tasks of design engineering, systems engineering, logistics, and user training [1]; no consistent methodology exists for assessing both the technical and economic benefits of PHM methods. Standardizing a specific set of data signal processing methods for PHM is perhaps ineffective, because each application requires diagnostic and prognostic techniques tailored to specific needs [1]. Roemer et al. [5] developed software for assessing the 
performance and effectiveness of PHM technologies being developed for a specific aircraft to help determine the effectiveness of PHM systems.

Despite the inconsistency of PHM methods, a prognostic approach should at least yield the predicted time of failure or degradation and its associated confidence interval. The assessment of failure or degradation requires performance metrics ranging from those for detection (to determine the system state) and isolation (to identify a root cause fault or failure mode) to prognosis (to determine remaining useful life) [5].

The development of PHM systems can be challenging due to the typical iterative process to result in a reliable system with effective data collection and analysis, even if the performance metrics are known. For example, the determination of performance thresholds for diagnostics or prognostics is a result of the analysis of various data sets, which would come from either seeded fault testing, accelerated mission testing, or actual field data in which known parameters are monitored and correlated with the progression of failure [5]. However, such data sets are typically expensive to acquire and represent less than $10 \%$ of the data sets required for performing the comprehensive verification and validation (V\&V) needed for PHM systems [5].

\subsection{NIST PHM Efforts}

In summary, PHM systems need to be developed and tested before implementation to enable improved decision-making for performance, safety, reliability, and maintainability of products and processes. However, standards appear to be lacking for PHM system development, data collection and analysis techniques, data management, system training, and software interoperability. National measurement institutes such as the United States' National Institute of Standards and Technology (NIST) may help to serve a role in the development of such standards. The first step is to identify the existing pertinent standards, which is a purpose of this document. 


\section{Published Standards}

Personnel from NIST conducted a survey of PHM-related standards to determine the industries and needs addressed by such standards and any similarities as well as potential gaps among the documents.

Table 1 categorizes the various standards related to PHM for manufacturing products and processes according to general topics based on the PHM process steps seen in Figure 1: 'Overview', 'Dependability analysis', 'Measurement techniques', 'Diagnostics and Prognostics', 'Data management', 'Training', and 'Applications'. If a standard has an ' $X$ ' mark in a corresponding general topic column in Table 1 , then that standard is largely applicable within that category. Some of the standards outline broad approaches for PHM (marked in the 'Overview' category) or are specific in guidance for PHM within a given application (marked in the 'Applications' category). Other standards focus on dependability analysis, measurement techniques, diagnostics and/or prognostics, PHM data management, or training related to maintenance of dependability systems, as denoted by the ' $X$ ' marks in Table 1 . This list of standards is not exhaustive, yet it is comprehensive enough for those in the manufacturing fields.

Table 1. Standards related to PHM for manufacturing.

\begin{tabular}{|c|c|c|c|c|c|c|c|c|c|c|c|}
\hline Organization & $\begin{array}{l}\text { Committee/ } \\
\text { Subcommittee }\end{array}$ & Standard & $\begin{array}{l}\text { Year } \\
\text { Issued }\end{array}$ & Title & 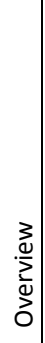 & 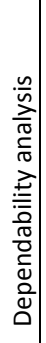 & 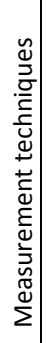 & 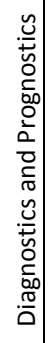 & 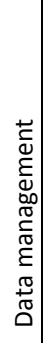 & 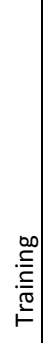 & 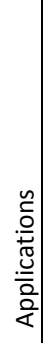 \\
\hline ATA & MSG & ATA MSG-3 & 2013 & $\begin{array}{lrr}\text { MSG-3: } & \text { Operator/Manufacturer } & \text { Scheduled } \\
\text { Maintenance } & \text { Development, Volume } 1 \text { - Fixed Wing } \\
\text { Aircraft } & \end{array}$ & $\mathrm{x}$ & & & & & & $\mathrm{x}$ \\
\hline IEC & 56 & IEC 61703 & 2001 & $\begin{array}{l}\text { Mathematical expressions for reliability, availability, } \\
\text { maintainability and maintenance support terms }\end{array}$ & $\mathrm{x}$ & & & & & & \\
\hline ISO & TC $108 / \mathrm{SC} 5$ & ISO 13372 & 2012 & $\begin{array}{l}\text { Condition monitoring and diagnostics of machines - } \\
\text { Vocabulary }\end{array}$ & $\mathrm{x}$ & & & & & & \\
\hline ISO & TC $108 / \mathrm{SC} 5$ & ISO 17359 & 2011 & $\begin{array}{l}\text { Condition monitoring and diagnostics of machines - } \\
\text { General guidelines }\end{array}$ & $\mathrm{x}$ & & & & & & \\
\hline SAE & E-32 & ARP1587B & 2007 & $\begin{array}{l}\text { Aircraft Gas Turbine Engine Health Management } \\
\text { System Guide }\end{array}$ & $\mathrm{x}$ & & & & & & $\mathrm{x}$ \\
\hline US Army & $\begin{array}{l}\text { Aviation } \\
\text { Engineering }\end{array}$ & ADS-79C-HDBK & 2012 & $\begin{array}{l}\text { Aeronautical Design Standard Handbook for Condition } \\
\text { Based Maintenance Systems for US Army Aircraft }\end{array}$ & $\mathrm{x}$ & & $\mathrm{x}$ & $\mathrm{x}$ & & & $\mathrm{x}$ \\
\hline IEC & 56 & IEC 60300-3-1 & 2003 & $\begin{array}{l}\text { Dependability management - Part 3-1: Application } \\
\text { guide - Analysis techniques for dependability - Guide } \\
\text { on methodology }\end{array}$ & & $\mathrm{x}$ & & & & & \\
\hline IEC & 56 & IEC 60300-3-3 & 2004 & $\begin{array}{l}\text { Dependability management - Part 3-3: Application } \\
\text { guide - Life cycle costing }\end{array}$ & & $\mathrm{x}$ & & & & & \\
\hline IEC & 56 & IEC 60812 & 2006 & $\begin{array}{l}\text { Analysis techniques for system reliability - Procedure } \\
\text { for failure mode and effects analysis (FMEA) }\end{array}$ & & $\mathrm{x}$ & & & & & \\
\hline IEC & 56 & IEC 61025 & 2006 & Fault tree analysis (FTA) & & $\mathrm{x}$ & & & & & \\
\hline IEC & 56 & IEC 61165 & 2006 & Application of Markov techniques & & $\mathrm{x}$ & & & & & \\
\hline SAE & AQPIC & J1739 & 2009 & $\begin{array}{l}\text { Potential Failure Mode and Effects Analysis in Design } \\
\text { (Design FMEA), Potential Failure Mode and Effects } \\
\text { Analysis in Manufacturing and Assembly Processes } \\
\text { (Process FMEA) }\end{array}$ & & $\mathrm{x}$ & & & & & \\
\hline SAE & G-11r & ARP5580 & 2001 & $\begin{array}{l}\text { Recommended Failure Modes and Effects Analysis } \\
\text { (FMEA) Practices for Non-Automobile Applications }\end{array}$ & & $\mathrm{x}$ & & & & & \\
\hline ISO/IEC & JTC $1 / \mathrm{SC} 7$ & ISO/IEC 15909-1 & 2004 & $\begin{array}{l}\text { Software and system engineering - High-level Petri } \\
\text { nets - Part 1: Concepts, definitions and graphical }\end{array}$ & & $\mathrm{x}$ & & & & & \\
\hline
\end{tabular}


This publication is available free of charge from http://dx.doi.org/10.6028/NIST.IR. 8012

\begin{tabular}{|c|c|c|c|c|c|c|c|c|c|c|}
\hline & & & & notation & & & & & & \\
\hline ISO/IEC & JTC $1 / \mathrm{SC} 7$ & ISO/IEC 15909-2 & 2011 & $\begin{array}{l}\text { Software and system engineering - High-level Petri } \\
\text { nets - Part 2: Transfer format }\end{array}$ & $x$ & & & & & \\
\hline ISO & TC $108 / \mathrm{SC} 2$ & ISO 13373-1 & 2002 & $\begin{array}{l}\text { Condition monitoring and diagnostics of machines - } \\
\text { Vibration condition monitoring - Part 1: General } \\
\text { procedures }\end{array}$ & & $x$ & & & & \\
\hline ISO & TC $108 / \mathrm{SC} 2$ & ISO $13373-2$ & 2005 & $\begin{array}{l}\text { Condition monitoring and diagnostics of machines - } \\
\text { Vibration condition monitoring - Part 2: Processing, } \\
\text { analysis and presentation of vibration data }\end{array}$ & & $x$ & & & & \\
\hline ISO & TC $108 / \mathrm{SC} 5$ & ISO 18434-1 & 2008 & $\begin{array}{l}\text { Condition monitoring and diagnostics of machines - } \\
\text { Thermography - Part 1: General procedures }\end{array}$ & & $x$ & & & & \\
\hline ISO & TC $108 / \mathrm{SC} 5$ & ISO 20958 & 2013 & $\begin{array}{l}\text { Condition monitoring and diagnostics of machine } \\
\text { systems - Electrical signature analysis of three-phase } \\
\text { induction motors }\end{array}$ & & $x$ & & & & \\
\hline ISO & TC $108 / \mathrm{SC} 5$ & ISO 22096 & 2007 & $\begin{array}{l}\text { Condition monitoring and diagnostics of machines - } \\
\text { Acoustic emission }\end{array}$ & & $x$ & & & & \\
\hline ISO & TC $108 / \mathrm{SC} 5$ & ISO 29821-1 & 2011 & $\begin{array}{l}\text { Condition monitoring and diagnostics of machines - } \\
\text { Ultrasound - Part 1: General guidelines }\end{array}$ & & $x$ & & & & \\
\hline ISO & TC $108 / \mathrm{SC} 5$ & ISO 13379-1 & 2012 & $\begin{array}{l}\text { Condition monitoring and diagnostics of machines - } \\
\text { Data interpretation and diagnostics techniques - Part } \\
\text { 1: General guidelines }\end{array}$ & & & $x$ & & & \\
\hline ISO & TC $108 / \mathrm{SC} 5$ & ISO 13381-1 & 2004 & $\begin{array}{l}\text { Condition monitoring and diagnostics of machines - } \\
\text { Prognostics - Part 1: General guidelines }\end{array}$ & & & $x$ & & & \\
\hline SAE & E-32 & AIR5871 & 2008 & Prognostics for Gas Turbine Engines & & & $x$ & & & $\mathrm{x}$ \\
\hline ISO & TC $184 / \mathrm{SC} 4$ & ISO 15531-1 & 2004 & $\begin{array}{l}\text { Industrial automation systems and integration - } \\
\text { Industrial manufacturing management data - Part 1: } \\
\text { General overview }\end{array}$ & & & & $x$ & & \\
\hline ISO & TC $184 / \mathrm{SC} 4$ & ISO 15531-42 & 2005 & $\begin{array}{l}\text { Industrial automation systems and integration - } \\
\text { Industrial manufacturing management data - Part 42: } \\
\text { Time Model }\end{array}$ & & & & $x$ & & \\
\hline ISO & TC $184 / \mathrm{SC} 4$ & ISO 15531-43 & 2006 & $\begin{array}{l}\text { Industrial automation systems and integration - } \\
\text { Industrial manufacturing management data - Part 43: } \\
\text { Manufacturing flow management data: Data model } \\
\text { for flow monitoring and manufacturing data exchange }\end{array}$ & & & & $x$ & & \\
\hline ISO & TC $184 / \mathrm{SC} 4$ & ISO 15531-44 & 2010 & $\begin{array}{l}\text { Industrial automation systems and integration - } \\
\text { Industrial manufacturing management data - Part 44: } \\
\text { Information modelling for shop floor data acquisition }\end{array}$ & & & & $x$ & & \\
\hline ISO & TC $184 / \mathrm{SC} 4$ & ISO 15926-1 & 2004 & $\begin{array}{l}\text { Industrial automation systems and integration - } \\
\text { Integration of life-cycle data for process plants } \\
\text { including oil and gas production facilities - Part 1: } \\
\text { Overview and fundamental principles }\end{array}$ & & & & $x$ & & \\
\hline ISO & TC $184 / \mathrm{SC} 4$ & ISO 15926-2 & 2003 & $\begin{array}{l}\text { Industrial automation systems and integration - } \\
\text { Integration of life-cycle data for process plants } \\
\text { including oil and gas production facilities - Part 2: } \\
\text { Data model }\end{array}$ & & & & $x$ & & \\
\hline ISO & TC $108 / \mathrm{SC} 5$ & ISO 13374-1 & 2003 & $\begin{array}{l}\text { Condition monitoring and diagnostics of machines - } \\
\text { Data processing, communication and presentation - } \\
\text { Part 1: General guidelines }\end{array}$ & & & & $x$ & & \\
\hline ISO & TC $108 / \mathrm{SC} 5$ & ISO 13374-2 & 2007 & $\begin{array}{l}\text { Condition monitoring and diagnostics of machines - } \\
\text { Data processing, communication and presentation - } \\
\text { Part 2: Data processing }\end{array}$ & & & & $x$ & & \\
\hline ISO & TC $108 / \mathrm{SC} 5$ & ISO 13374-3 & 2012 & $\begin{array}{l}\text { Condition monitoring and diagnostics of machines - } \\
\text { Data processing, communication and presentation - } \\
\text { Part 3: Communication }\end{array}$ & & & & $x$ & & \\
\hline ISO & TC $184 / \mathrm{SC} 5$ & ISO 18435-1 & 2009 & $\begin{array}{l}\text { Industrial automation systems and integration - } \\
\text { Diagnostics, capability assessment and maintenance } \\
\text { applications integration - Part 1: Overview and } \\
\text { general requirements }\end{array}$ & & & & $x$ & & \\
\hline ISO & TC $184 / \mathrm{SC} 5$ & ISO 18435-2 & 2012 & $\begin{array}{l}\text { Industrial automation systems and integration - } \\
\text { Diagnostics, capability assessment and maintenance } \\
\text { applications integration - Part 2: Descriptions and } \\
\text { definitions of application domain matrix elements }\end{array}$ & & & & $x$ & & \\
\hline ISO & TC $108 / \mathrm{SC} 5$ & ISO 18436-1 & 2012 & $\begin{array}{l}\text { Condition monitoring and diagnostics of machines - } \\
\text { Requirements for qualification and assessment of }\end{array}$ & & & & & $x$ & \\
\hline
\end{tabular}




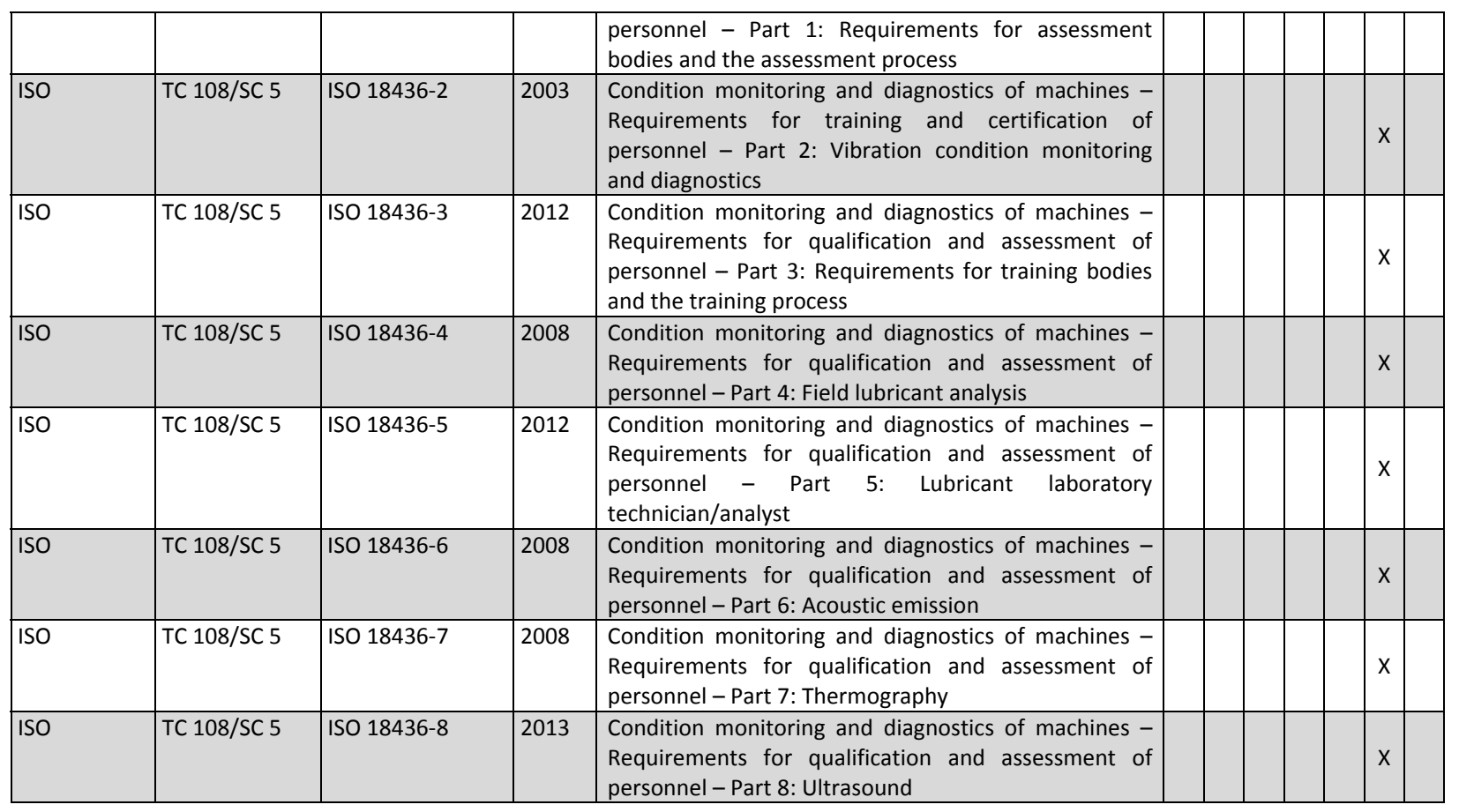

These standards were developed by various national and international organizations: the Air Transport Association (ATA), the International Electrotechnical Commission (IEC), the International Organization for Standardization (ISO), the Society of Automotive Engineers (SAE), and the United States Army (US Army). Specifically, each standard is developed within a technical committee (TC) or subcommittee (SC) of each organization, composed of various experts from industry, government, and academia. The committee that produces each standard is listed in Table 1 for reference purposes.

For example, four subcommittees within ISO are responsible for the associated standards in Table 1: TC 108/SC 2, TC 108/SC 5, TC 184/SC 4, and TC 184/SC 5. The ISO/TC 108/SC 5 group (members from 33 countries [6]) is tasked with the development of standards related to condition monitoring and diagnostics of machine systems in which physical parameters are periodically or continuously sensed for the support of machine maintenance decisions [7]. The Acoustical Society of America is accredited by the American National Standards Institute (ANSI) to organize and manage the U.S. Technical Advisory Group (TAG) that gives U.S. stakeholders (including NIST) a voice in ISO/TC 108 standards development. While TC 108/SC 5 relates to the condition monitoring and diagnostics of machine systems, TC 108/SC 2 deals specifically with the measurement and evaluation of mechanical vibration and shock for machines, vehicles, and structures, and ISO/TC 184 is scoped with the standardization of automation systems and their integration within manufacturing [8]. As such, ISO/TC 184/SC 4 (covering 'industrial data') has numerous standards dealing with the management of industrial manufacturing data.

In the following subsections, the various standards seen in Table 1 are outlined according to their main associated category.

\subsection{Overview}


Standards with general guidance about the creation of PHM systems are indicated under the 'Overview' category within Table 1 . Such standards are a natural starting point during the creation of PHM systems, because these documents outline the factors influencing condition monitoring and provide guidance for the monitoring of components and/or sub-systems.

As the parent document of a group of standards that cover condition monitoring and diagnostics, ISO 17359 [9] was developed by ISO/TC 108/SC 5 ("Condition monitoring and diagnostics of machines") to provide the general procedures for setting up a condition monitoring program for all machines, e.g., the generic approaches to setting alarm criteria and carrying out diagnosis and prognosis. ISO 17359 outlines the condition monitoring procedure for a general manufacturing process (see Figure 2), factors influencing condition monitoring, a list of issues affecting equipment criticality (e.g., cost of machine down-time, replacement cost), and a table of condition monitoring parameters (such as temperature, pressure, and vibration) for various machine types. ISO 17359 also presents multiple examples of tables showing the correlation of possible faults (e.g., air inlet blockage, seal leakage, and unbalance) with symptoms or parameter changes. Furthermore, ISO 17359 shows an example of a typical form for recording monitoring information, as seen in Figure 3. 
Overview

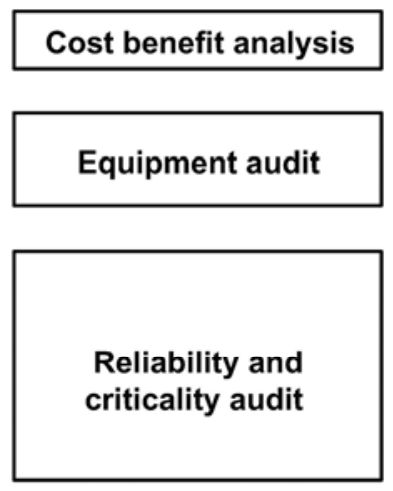

Select appropriate maintenance strategy
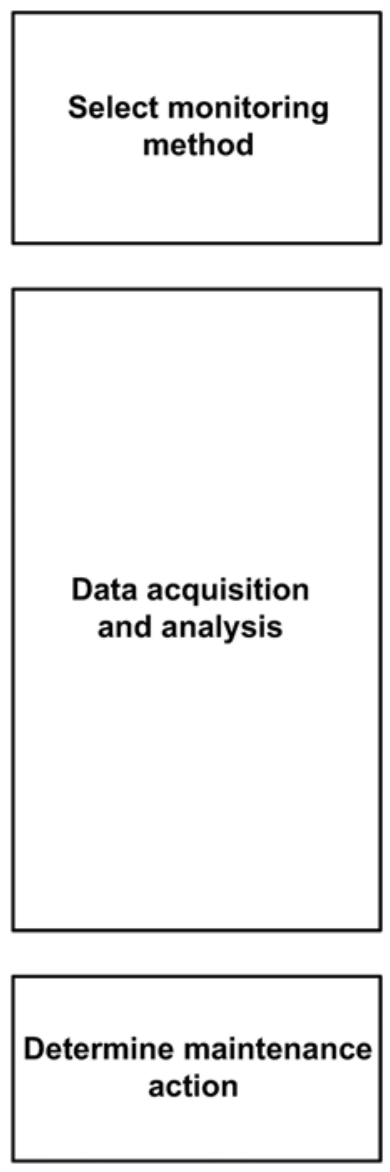

Review
Detail

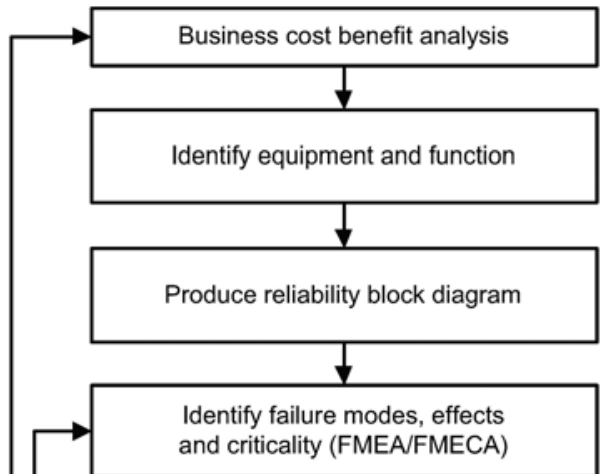

(FMEA/FMECA)

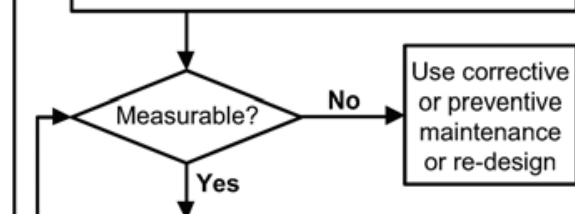

dentify parameter(s) to be measured

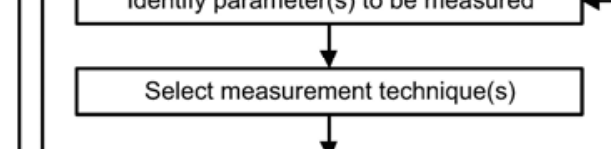

Select measurement location(s)

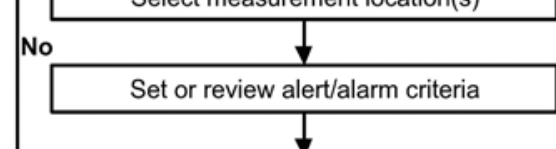

Take measurements and trend readings

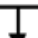

Compare with alert/alarm criteria

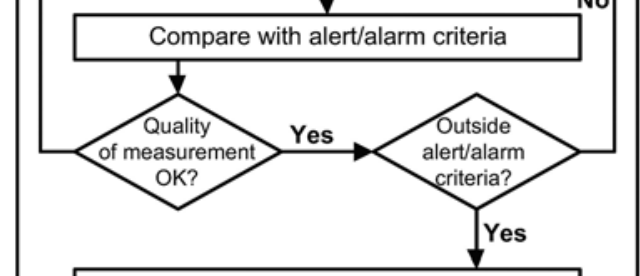

Perform diagnosis and prognosis

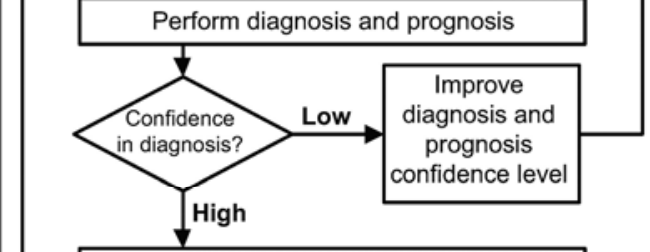
Determine required maintenance action Carry out maintenance action

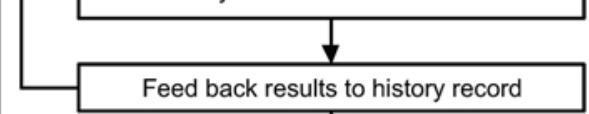

Feed back results to history record

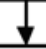

Review and measure effectiveness

\section{Comments}

Return on investment analysis Life cycle cost

Plant survey, on-site discussion Process diagrams

Codify and tag assets

Process, instrument and power line diagrams

Site drawings

Discussion with operations

and maintenance personnel

Maintenance history

Pareto analysis

Root cause failure analysis

Reliability databases

For measurable faults, consider condition monitoring, otherwise

consider alternatives:

- Corrective or preventive

- Re-design or possibly don't use

Fault and failure characteristics Specific International Standards Discussion with maintenance

personnel

Condition monitoring expertise

Equipment suppliers

Available instrumentation

Select transducers

Select CM system

Configure $\mathrm{CM}$ system

Set up measurement sequence

Take initial measurements

Set or review initial alert criteria

Schedule measurements

Data acquisition

Take baselines

Are measurements reasonable?

- Poor readings

- Transducer fault

- Adjacent machines

- Machine not running

Compare to alert/alarm criteria

Carry out diagnosis

Carry out prognosis

Review symptoms, rules, etc.

To improve confidence

- More measurements

Other techniques

- Correlate measurements

Determine maintenance action Carry out maintenance action Feedback results and history

Record spares used

Confirm diagnosis after

maintenance action completed

Review alert/alarm criteria Key performance indicators Review available techniques

Figure 2. Condition monitoring procedure flowchart from ISO 17359 [9]. [This excerpt is taken from ISO 17359:2011, Figure 1 on page 2, with the permission of ANSI on behalf of ISO. (c) ISO 2014 - All rights reserved]. 


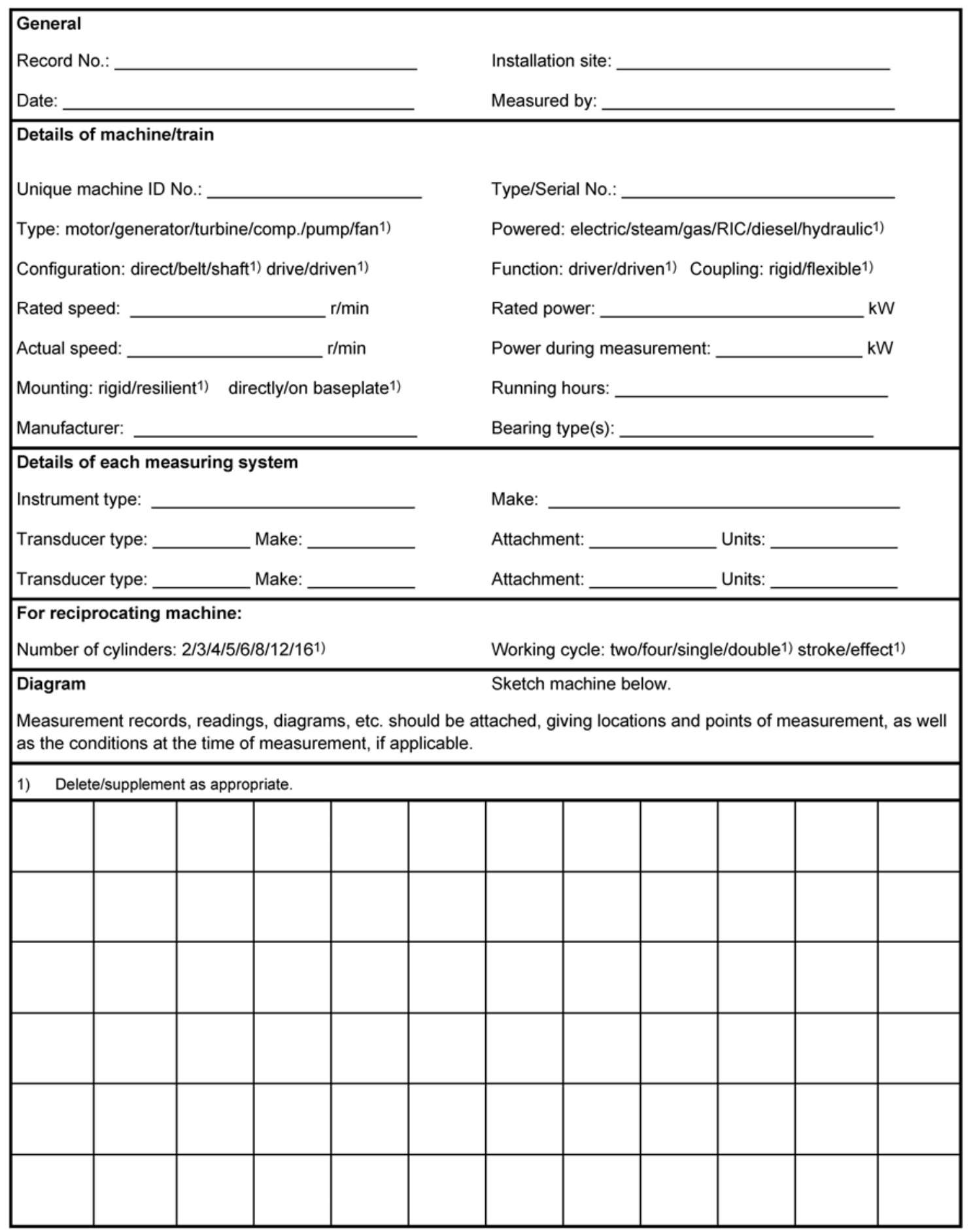

Figure 3. Form for recording typical machine details from ISO 17359 [9]. [This excerpt is taken from ISO 17359:2011, Table C.1 on page 21, with the permission of ANSI on behalf of ISO. (c) ISO 2014 - All rights reserved].

Another standard that provides guidance for PHM systems development is MSG-3, a document titled "Operator/Manufacturer Scheduled Maintenance Development." The Maintenance Steering Group 
(MSG) of the Air Transport Association (ATA) developed MSG-3, which is used for developing maintenance plans for aircraft, engines, and systems [10]. MSG-3 is used by Industry Steering Committees (ISCS), comprised of aircraft, engine, propeller, and appliance manufacturers, for the development of minimum initial maintenance requirements for all new or derivative aircraft in the United States. Each ISC-generated document for an aircraft is then approved by the Federal Aviation Administration (FAA) before the aircraft enters service. MSG-3 is a top-down approach to determine the consequences (safety, operational, and economic) of failure, starting at the system level and working down to the component level [11]. Failure effects are divided into five categories, and if the consequences of failure cannot be mitigated, then redesign becomes necessary. For example, the MSG3 process led to mandatory design changes for the Boeing 787-8's in-flight control and lightning/HIRF (High-Intensity Radiated Field) protection systems. Furthermore, the MSG-3 methodology helps improve safety while reducing maintenance-related costs up to 30 percent. In fact, MSG-3 improves previous approaches that led to unnecessary maintenance tasks and potential supplemental failures [11].

Similar in scope to the standards just described, an Aeronautical Design Standard (ADS) Handbook (HDBK), ADS-79C-HDBK, was developed by the U.S. Army to describe the Army's condition-based maintenance (CBM) system for military aircraft systems [1]. $C B M$ is the preferred maintenance approach for Army aircraft systems, yet ADS-79C-HDBK is broad enough for application in other industries to be included in the 'Overview' category of Table 1. The document provides guidance and standards for use by all Department of Defense (DoD) agencies in the development of CBM data acquisition, signal processing software, and data management. Furthermore, ADS-79C-HDBK is in the spirit of the previous use of reliability centered maintenance (RCM) methods by the DoD to avoid the consequences of material failure. Failure mode, effects, and criticality analysis (FMECA) identifies where CBM should be utilized, but RCM is used to determine the most appropriate failure management strategy. Additionally, ADS-79C-HDBK is supported by the Machinery Information Management Open Standards Alliance (MIMOSA), a United States association of industry and government, and follows the information flow structure detailed in the ISO 13374 series [1]. Even though CBM systems can be valued for increasing the dependability of mission-oriented systems, the Army does not intend to make missions dependent upon such systems, because missions must proceed even if CBM systems are inoperative [1]. For example, adding sensors with associated signal processing to legacy aircraft can increase the overall system reliability as long as the hardware is not mission-critical. However, years of work may be needed to achieve in-flight PHM via field tests with faults [1].

ADS-79C-HDBK describes the elements of a CBM system architecture with technical considerations for Army aviation in twelve separate appendices (e.g., fatigue life management, flight test validation, vibration based diagnostics, and data integrity). ADS-79C-HDBK defines CBM-related terms ('airworthiness', 'critical safety item', 'exceedance', etc.) and assists in the development of CBM systems for both legacy and new aircraft. As seen in Figure 4, the appendices of ADS-79C-HDBK are used to help developers to identify components to maintain, plan for data acquisition, perform fault testing, design the software and hardware elements, and validate CBM algorithms. 


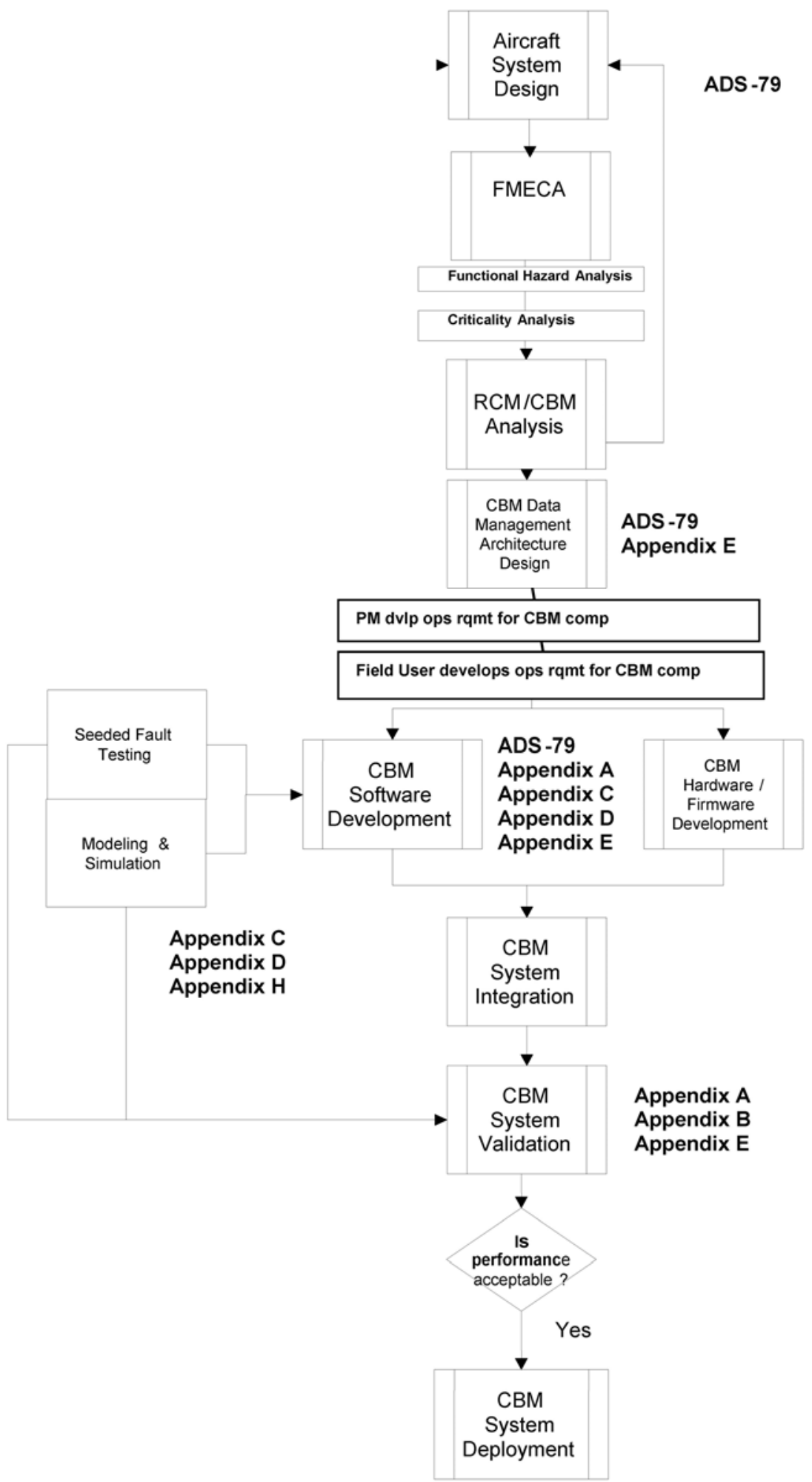

Figure 4. CBM development for new acquisition from ADS-79C-HDBK [1]. [This excerpt is taken from ADS-79C-HDBK, Figure 4 on page 31, with the permission of the Aviation Engineering Directorate of the U.S. Army]. 


\subsection{Dependability Analysis}

As discussed in Section 2.1, one aspect of the creation of PHM systems is the determination of what components or subsystems should be redesigned, changed, or monitored. In general, a dependability analysis involves the identification of the reliability, availability, and maintainability of the entire system, its subsystems, and its components [12]. An essential part of system design is the definition of dependability requirements for subsystems, so the most effective system architecture can be determined. Only manufacturing process design changes can improve the inherent dependability performance measures [12]. Such changes should occur sooner rather than later, necessitating the dependability analysis in the early phases of PHM system development, as seen in the upper portion of the flowchart in Figure 4.

Various methods exist to identify the failure modes of the system, and experts in the dependability and system engineering field should select the most applicable method early in the program development. For example, bottom-up (elements) methods are used to identify the failure modes at the component level, which are then used to determine the corresponding effect on higher-level system performance. Top-down (functional) methods are used to identify undesirable system operations by starting from the highest level of interest (the top event) and proceeding to successively lower levels [12]. Usually bottom-up methods are more straightforward in application, while top-down methods require more thought and are hence more prone to errors. Bottom-up dependability analysis methods include event tree analysis, failure mode and effects analysis (FMEA), and hazard and operability study (HAZOP), while top-down methods includes fault tree analysis (FTA), Markov analysis, Petri net analysis, and reliability block diagrams (RBD).

IEC 60300-3-1 gives a general overview of the common dependability analysis techniques, including fault tree analysis, Markov analysis, Petri net analysis, and stress-strength analysis [12]. IEC 60300-3-1 presents tables outlining the general applicability and characteristics of each method (see Figure 5) as well as concise summaries of each method (including benefits, limitations, and examples) in a separate informative annex. The methods can be categorized according to their purpose of either fault avoidance (e.g., stress-strength analysis), architectural analysis and dependability allocation (bottom-up methods, such as FMEA, or top-down methods, such as FTA), or estimation of measures for basic events (such as failure rate prediction). However, IEC 60300-3-1 states that no single dependability analysis method is sufficiently comprehensive, such that composite approaches have been used in practice [12]. Ultimately, analysis based on either a hardware (bottom-up), functional (top-down), or combination approach should be used to assess high risk items and provide corrective actions [13]. 


\begin{tabular}{|c|c|c|c|c|c|c|c|c|c|c|c|c|c|c|}
\hline Method & 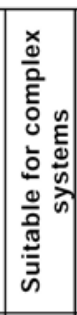 & 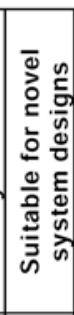 & 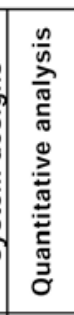 & 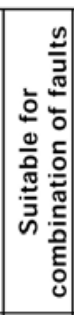 & 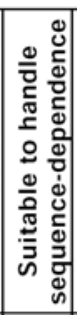 & 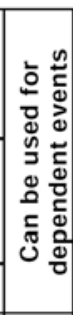 & 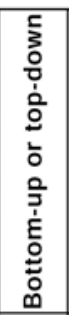 & 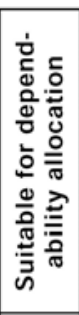 & 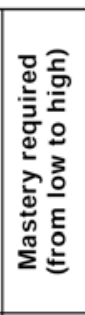 & 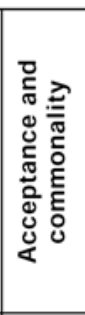 & $\begin{array}{l}5 \\
\vdots \\
0 \\
0 \\
ㄱ\end{array}$ & 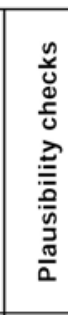 & $\begin{array}{l}\frac{n}{0} \\
\vdots \\
0 \\
0 \\
\frac{0}{0} \\
\frac{0}{0} \\
\frac{\pi}{\pi} \\
\frac{\pi}{2}\end{array}$ & 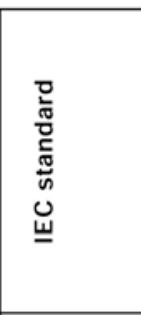 \\
\hline $\begin{array}{l}\text { Failure rate } \\
\text { prediction }\end{array}$ & No & Yes & Yes & No & No & No & $\mathrm{BU}$ & Yes & Low & High & Avg & Yes & High & 61709 \\
\hline $\begin{array}{l}\text { Fault tree } \\
\text { analysis (FTA) }\end{array}$ & Yes & Yes & Yes & Yes & No & No & TD & Yes & Avg & High & Avg & Yes & High & 61025 \\
\hline $\begin{array}{l}\text { Event tree } \\
\text { analysis (ETA) }\end{array}$ & NR & NR & Yes & NR & Yes & Yes & BU & NR & High & Avg & Avg & Yes & Avg & \\
\hline $\begin{array}{l}\text { Reliability block } \\
\text { diagram } \\
\text { analysis (RBD) }\end{array}$ & NR & NR & Yes & Yes & No & No & TD & Yes & Low & Avg & Avg & Yes & Avg & 61078 \\
\hline $\begin{array}{l}\text { Markov } \\
\text { analysis }\end{array}$ & Yes & Yes & Yes & Yes & Yes & Yes & TD & Yes & High & Avg & High & No & Avg & 61165 \\
\hline $\begin{array}{l}\text { Petri net } \\
\text { analysis }\end{array}$ & Yes & Yes & Yes & Yes & Yes & Yes & TD & Yes & High & Low & High & No & Low & \\
\hline $\begin{array}{l}\text { Failure mode } \\
\text { and effects } \\
\text { analysis } \\
\text { (FMEA) }\end{array}$ & NR & NR & Yes & No & No & No & BU & NR & Low & High & Low & Yes & High & 60812 \\
\hline HAZOP studies & Yes & Yes & No & No & No & No & BU & No & Low & Avg & Low & Yes & Avg & 61882 \\
\hline $\begin{array}{l}\text { Human } \\
\text { reliability } \\
\text { analysis }\end{array}$ & Yes & Yes & Yes & Yes & Yes & Yes & BU & No & High & High & Avg & Yes & Avg & \\
\hline $\begin{array}{l}\text { Stress-strength } \\
\text { analysis }\end{array}$ & NA & NA & Yes & NA & NA & No & NA & No & High & Avg & High & Yes & Avg & \\
\hline Truth table & No & Yes & Yes & Yes & No & No & NA & Yes & High & Avg & High & No & Low & \\
\hline $\begin{array}{l}\text { Statistical } \\
\text { reliability } \\
\text { methods }\end{array}$ & Yes & Yes & Yes & Yes & Yes & Yes & NA & NR & High & Avg & High & Avg & Low & $60300-3-5$ \\
\hline \multicolumn{15}{|c|}{$\begin{array}{l}\text { NR May be used for simple systems, Not recommended as a stand-alone method, to be used jointly with } \\
\text { other methods. } \\
\text { TD Top-down. } \\
\text { BU Bottom-up. } \\
\text { Avg Average. } \\
\text { NA The criterion is not applicable with respect to this method. }\end{array}$} \\
\hline
\end{tabular}

Figure 5. Characteristics of various dependability analysis methods from IEC 60300-3-1 [12]. [Copyright (C) 2003 IEC Geneva, Switzerland. www.iec.ch].

To support the quantification of dependability, the IEC technical committee 56 (Dependability) developed IEC 61703 to provide the mathematical expressions for reliability, availability, maintainability, and other maintenance terms [14]. The expressions are grouped into classes for various items: nonrepaired items, repaired items with zero time to restoration, and repaired items with non-zero time to 
restoration. Numerous equations are provided in IEC 61703 for the generic case of an exponentially distributed time to failure.

While IEC 61703 and IEC 60300-3-1 contain overviews of various dependability expressions and analysis methods, other standards focus on guidance for use of a particular analysis method, whether bottom-up or top-down. The following subsections summarize those particular standards indicated under the 'Dependability analysis' category within Table 1.

\subsubsection{Bottom-Up Methods}

\subsubsection{FMEA and FMECA}

Failure modes and effects analysis (FMEA) is a formal and systematic approach to identify potential failure modes of a system along with their causes and immediate and final effects on system performance [15] through the usage of information about failure ("What has failed?") and its effects ("What are the consequences?") [16]. It is advantageous to perform FMEA early in the development of a product or process so that failure modes can be eliminated or mitigated as cost effectively as possible. FMEA can be used to identify failures (hardware, software, human performance) and improve reliability and maintainability via information for the development of diagnostic and maintenance procedures. The process begins with a hierarchical decomposition of the system and is followed by an analysis beginning with lowest level elements (bottom-up approach) [15].

FMEA has been modified for various purposes; failure modes, effects and criticality analysis (FMECA) is an extension of FMEA that uses a metric called criticality to rank the severity of failure modes [15] as well as the probability of each failure mode [16]. FMECA is composed of two steps (FMEA and criticality analysis (CA)) to determine the effect of each failure on system operation by identifying single failure points and ranking each failure according to its severity. FMECA is essential during conceptual design through development of a system to identify all failure modes, especially the catastrophic ones, so that they can be eliminated or minimized through redesign [13]. The over-arching goal of FMECA is to support the design-making process, like all dependability analyses.

FMEA can also be applied to manufacturing and assembly processes, in which it is called process FMEA (PFMEA). PFMEA enables engineers to identify unacceptable effects of failure modes (such as those for part binding, cracking etc.). Engineers then develop manufacturing control plans as well as "document the rationale behind process changes to guide development of future manufacturing and assembly processes" [16]. PFMEA usually leads to cost improvements [15].

One standard concerning FMEA and FMECA is MIL-P-1629, which was issued by the U.S. military in 1949. In 1980, the U.S. Department of Defense issued a revision as MIL-STD-1629A. This standard establishes requirements and procedures for performing a systematic FMECA for each functional or hardware failure related to mission success, personnel and system safety, system performance, maintainability, and maintenance requirements. Specifically, MIL-STD-1629A provides a functional block diagram example, a reliability block diagram example, an equation to calculate failure mode criticality, and FMEA, CA, and FMECA worksheet formats [13]. 
MIL-STD-1629A was partially revised in 1984 but canceled in 1998. At that time, the DoD was transitioning to utilize more commercial products and practices. The Defense Standards Improvement Council (DSIC) was created to oversee the standardization reform process. Consequently, the foreword to SAE ARP5580 ('Recommended Failure Mode and Effects Analysis (FMEA) Practices for NonAutomobile Applications') from SAE's G-11r Reliability Committee recognizes SAE ARP5580 as essentially an update of MIL-STD-1629A based on input from industry, Government, and academia [16].

SAE ARP5580 describes the procedure for how to perform FMEA. This procedure includes a basic methodology for the three FMEA classifications related to how the failure modes are postulated: functional FMEA (at the conceptual design level), interface FMEA (before the detailed design of the interconnected subsystems), and detailed FMEA (performed when detailed designs are available) [16]. SAE ARP5580 can be used to assess the reliability of systems with increasing impact when FMEA is performed at increasing levels of detail during development of hardware or software. FMEA can continue throughout the entire life of a program, from conceptual design to maintenance [16]. The FMEA process itself can be improved, and SAE ARP5580 states that possible improvements to FMEA are the inclusion of timing effects, including simultaneous failure modes and their delayed consequences.

SAE ARP5580 provides many definitions of key terms (e.g., 'allocation', 'criticality', and 'fault tree') and other items typically included within FMEA. SAE ARP5580 provides ground rules (with an example), numbering conventions for functional FMEA to describe systems according to a hierarchy (subsystems, components, software, etc.) with well-defined inputs and outputs, and examples of severity classifications for military, aerospace, and automobile industries. SAE ARP5580 also gives failure mode probability equations and an example of qualitative probability intervals for the automobile industry. An integrator must create an overall system FMEA, which may require a standardized worksheet format for FMEA information [16].

Even though FMEA has been useful to identify, rank, and mitigate potential failure modes in the automobile industry since the late 1960s, a growing need developed for changes in failure mode ranking criteria and the risk priority number (RPN) [17]. Hence, SAE J1739 was revised in 2009 as a basis for the development of an effective design FMEA (DFMEA) and a FMEA for manufacturing and assembly processes (PFMEA) [17]. Based on references (e.g., SAE ARP5580 and IEC 60812) and input from original equipment manufacturers (OEMs) and their suppliers, SAE J1739 was revised to include current terms, requirements, ranking charts, and worksheets for the identification and mitigation of failure mode risks. Examples are given for a block or boundary diagram (for DFMEA), a process flow diagram (for PFMEA), and design and process FMEA worksheets related to the auto industry. Also, suggestions are given in tabulated form for design and process FMEA severity $(S)$ evaluation criteria as well as those for occurrence (O) and detection (D) evaluation criteria. Even though the RPN is defined as the product $\mathrm{S} \times$ $\mathrm{O} \times \mathrm{D}$, SAE J1739 warns that this number, which ranges from 1 to 1000, should not be used as the sole metric for risk evaluation via thresholding. Finally, the document has various examples of lists of items to consider for inputs (e.g., warranty, recalls), outputs (such as high-severity failure modes, action plans for design, and worksheets), design controls, functions, requirements, and failure modes for the FMEA process [17].

Another standard that gives guidance to produce successful FMEA and FMECA is IEC 60812, which was developed by the IEC technical committee 56 (Dependability) [15]. IEC 61025 ('Fault tree analysis (FTA)') and IEC 61078 ('Analysis techniques for dependability - Reliability block diagram method') are normative references for IEC 60812. IEC 60812 is a standard that provides steps, terms, criticality measures (potential risk, risk priority number, criticality matrix), failure modes, basic principles, 
procedures, and examples for FMEA and FMECA. Figure 6 shows a flowchart of the general FMEA process. IEC 60812 advises that while FMECA may be a very cost-effective method for assessing failure risks, a probability risk analysis (PRA) is preferable to a FMECA; FMECA should not be the only basis for judging risks, especially since risk priority numbers have deficiencies such as inadequate scaling, as discussed in SAE J1739. FMEA has limitations in that it is difficult and tedious to apply to complex systems with multiple functions [15].

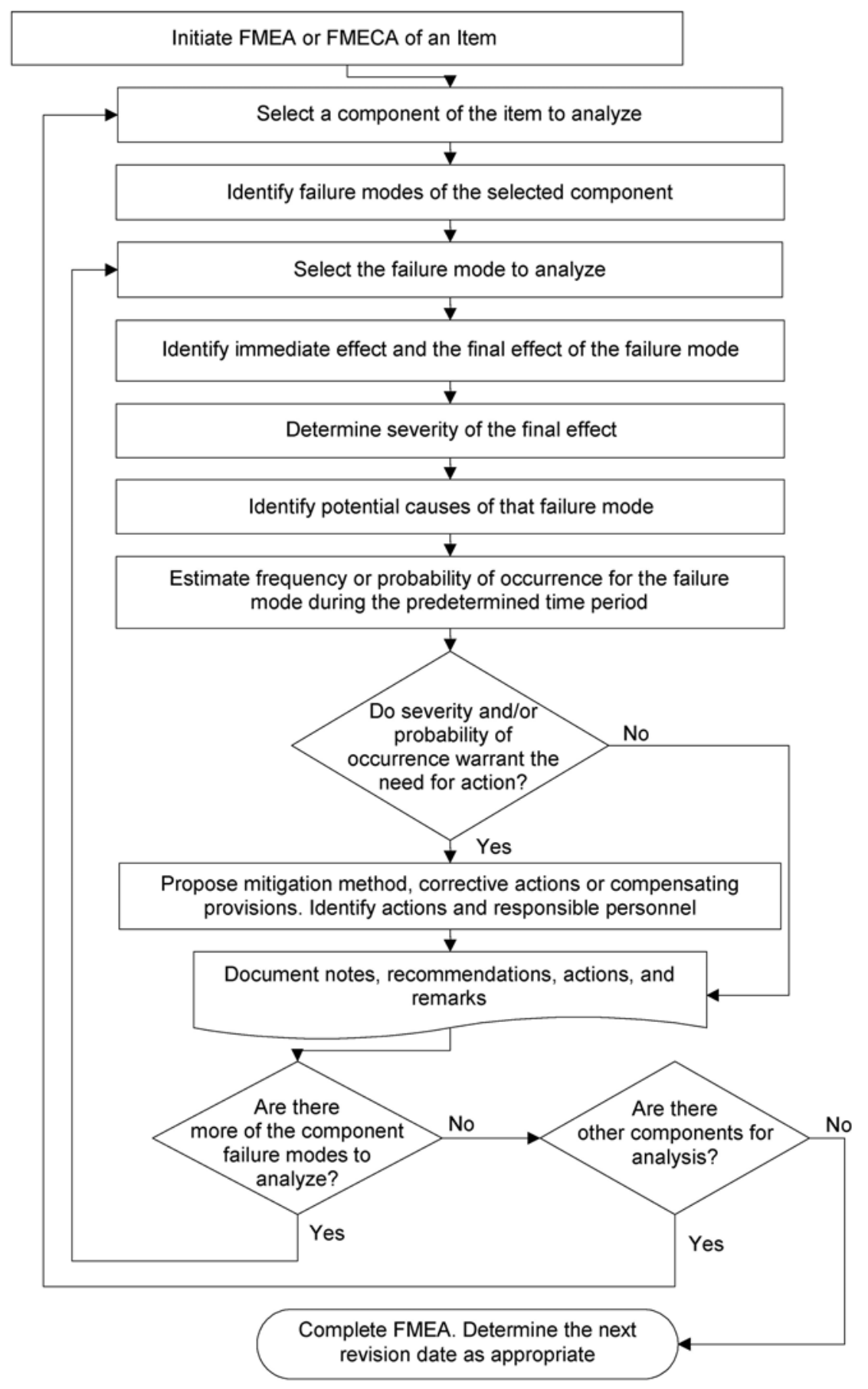

Figure 6. FMEA flowchart from IEC 60812 [15]. [Copyright @ 2006 IEC Geneva, Switzerland www.iec.ch]. 


\subsubsection{Top-Down Methods}

As discussed in the previous section, FMEA/FMECA is a widely used analysis method for dependability. FMEA, as an inductive (bottom-up) method of analysis, is mainly used to complement other approaches such as fault tree analysis (FTA), a deductive (top-down) method. IEC 60812 states that it may be difficult to decide whether an inductive or deductive approach should be used at the design stage [15]. However, a deductive approach such as FTA is generally preferred over FMEA for industrial systems where the levels of risk are identified. FMEA is more applicable for systems with components related by mainly series failure logic, while FTA is generally preferred for systems with multiple failure modes and complex failure logic and redundancy [15].

\subsubsection{Fault Tree Analysis (FTA)}

FTA is a technique that is helpful in overcoming the current limitations of FMEA [16]. FTA is a deductive method used to determine the causes that can lead to the occurrence of a defined outcome, called the 'top event' [18]. FTA achieves this goal through use of a fault tree, such as the one shown in Figure 7. A fault tree is a graphical representation of how faults or events interact to possibly cause the top event. Construction proceeds down the tree, continually approaching the desired lower level of mechanism and mode. The lowest possible level contains the primary (bottom) events, the individual causes of potential failures or faults [18]. Thus, FTA identifies potential problems caused by design, operational stresses, and flaws in product manufacturing processes. Hence, fault trees should be developed early during system design and continue throughout the development of a product [18]. Fault trees are used in multiple industries, such as in automotive, nuclear, and manufacturing plants. 


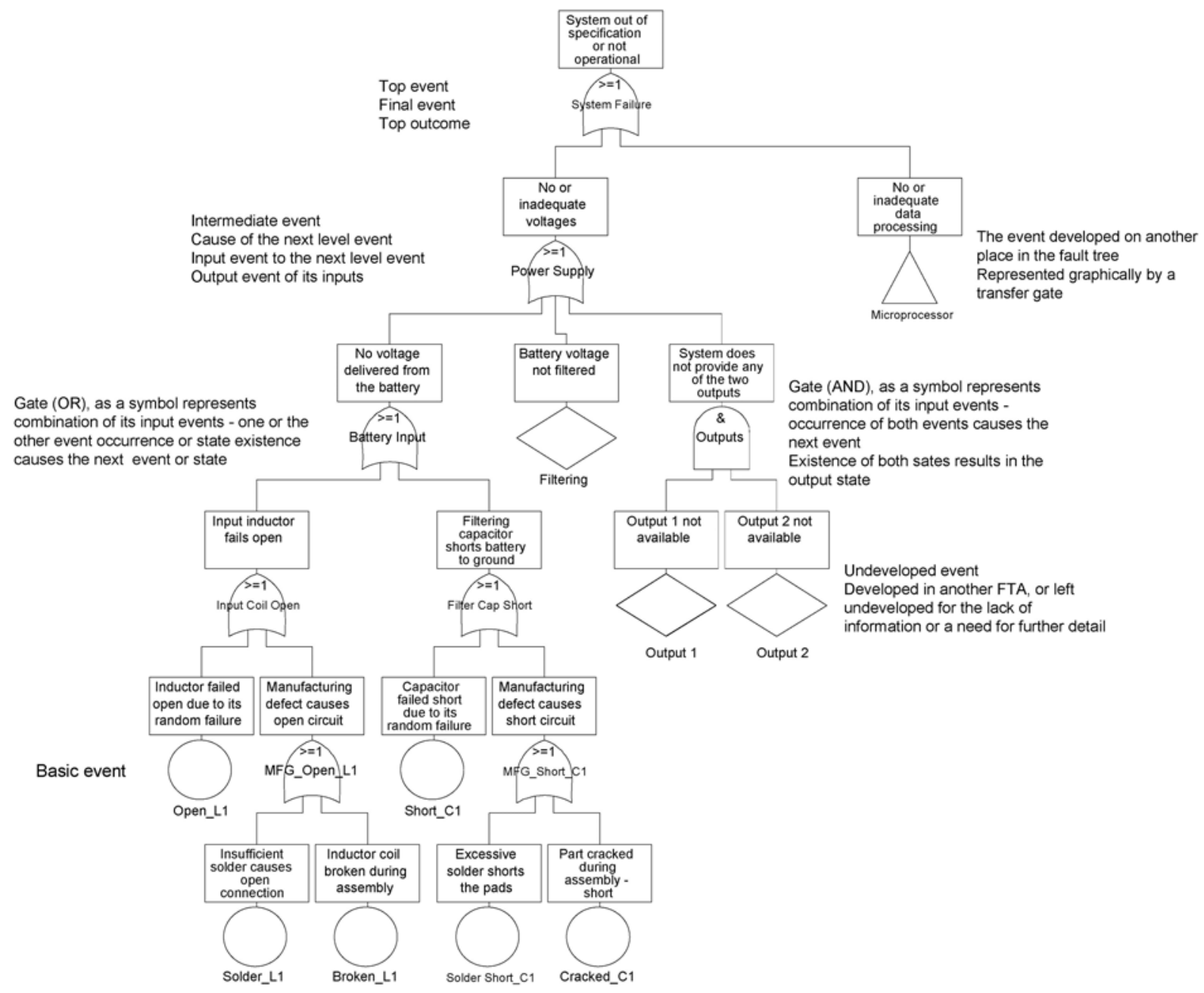

Figure 7. Explanation of terms used in fault tree analysis from IEC 61025 [18]. [Copyright (C) 2006 IEC Geneva, Switzerland. www.iec.ch].

In contrast to other reliability analyses, FTA includes only those events and their interactions that contribute to the occurrence of the top event. In fact, several differences exist among FTA and FMEA. First, FTA is a top-down approach, while FMEA is a bottom-up approach. Second, FTA accomplishes single and multiple failure analysis via the interaction between faults or events representing failure modes. These interactions are not possible in a regular FMEA. Third, FTA is a method for causal analysis of undesirable events, while FMEA is a method for identification of basic events or hazards [18].

To enable the use of fault tree analysis, the IEC technical committee 56 developed IEC 61025, which addresses the two approaches to FTA: a qualitative or logical approach (Method A), used largely in the nuclear industry, and a quantitative or numerical approach (Method B) that results in a quantitative probability of the occurrence of a top event within manufacturing and other industries [18]. IEC 61025 describes FTA with its definitions (e.g., 'top event', 'gate', and 'event'), steps (fault tree construction, analysis, reporting, etc.), and fault tree symbols (for static and dynamics gates). Figure 8 shows a fault tree with different gate types such as 'AND' and 'OR.' 


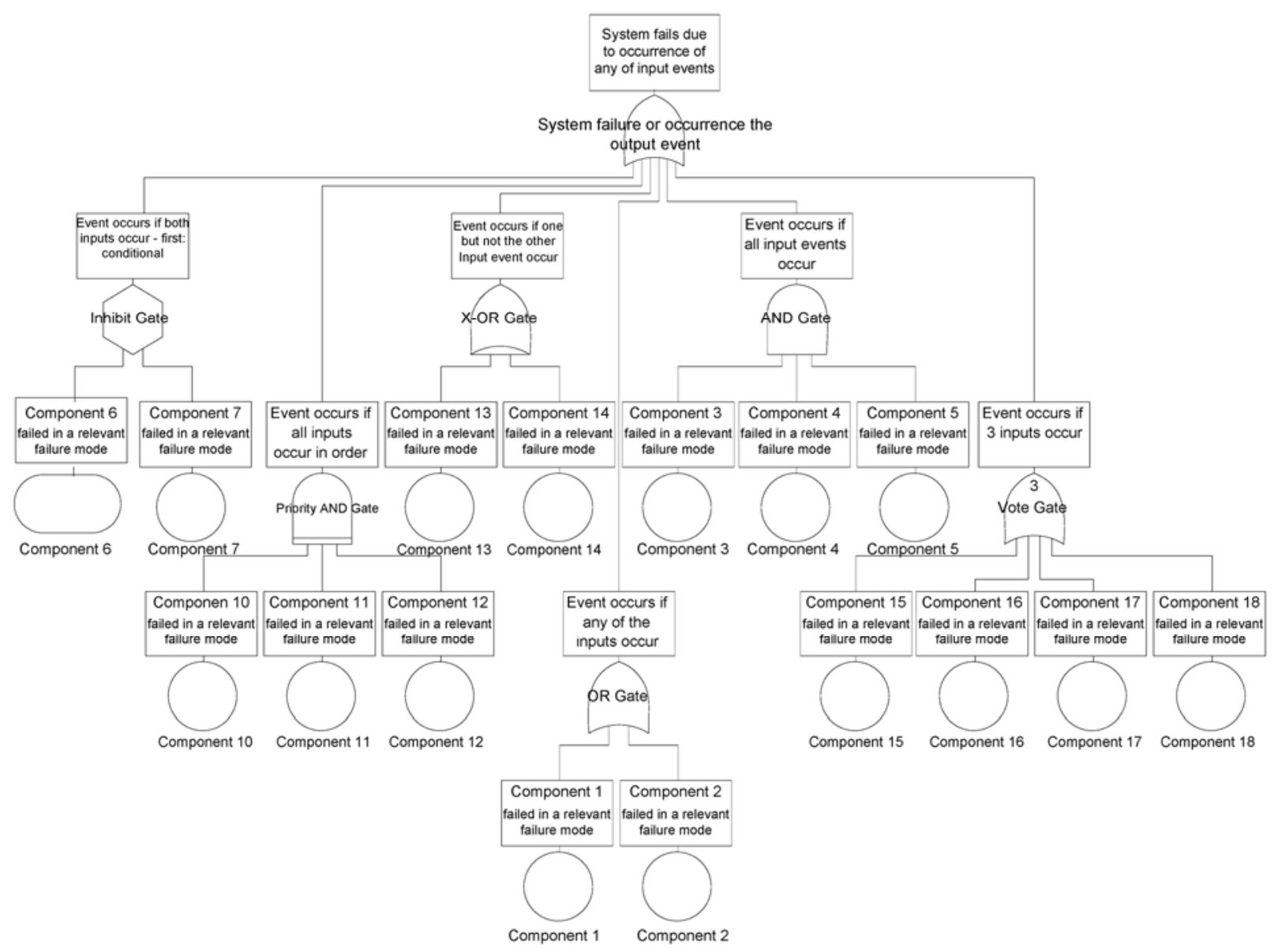

Figure 8. Example of fault tree showing various types of gates from IEC 61025 [18]. [Copyright (C 2006 IEC Geneva, Switzerland. www.iec.ch].

FTA can be extended to complex systems with fault trees created for separate but linked events, with these fault trees subsequently combined. IEC 61025 provides the mathematics for reliability of series and parallel (redundant) systems, which uses probabilistic data at the component level from reliability or actual field test data to determine the probability of the occurrence of the 'top event'. Proper mathematical treatment includes 'disjointing', a series of algebraic operations that ensures that the common branch (or common-cause failure) is included only once in the 'top event' probability calculations [18].

\subsubsection{Markov Analysis}

Markov analysis is another method to determine the dependability and safety of systems. The IEC technical committee 56 produced IEC 61165, a standard that gives an overview of the Markov technique [19]. Markov techniques use state transition diagrams to represent the temporal behavior of a system, which is a connected number of elements, each of which has only one of two states: up or down. An example of such a diagram is shown in Figure 9. The entire system transitions from one state to another as the system elements fail or are restored according to defined failure and restoration rates. Each state in Figure 9 is represented by a circled number, and transitions are represented by arrows with failure rates $\left(\lambda_{1}, \lambda_{2}\right.$, etc.) or restoration rates $\left(\mu_{1}, \mu_{2}\right.$, etc.). 


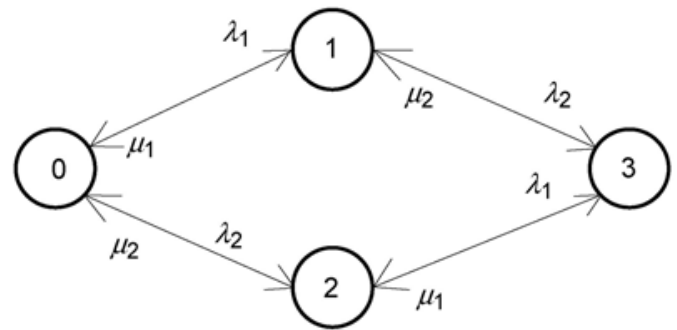

Figure 9. Example state transition diagram used for Markov techniques from IEC 61165 [19]. [Copyright (C) 2006 IEC Geneva, Switzerland. www.iec.ch].

Markov techniques are especially useful for the analysis of redundant systems. One advantage is that maintenance strategies can be modeled with Markov techniques, while other techniques such as fault tree analysis (FTA) and reliability block diagrams (RBDs) do not account for complex maintenance strategies. The flexibility of Markov techniques is offset by their complexity with the increasing number of system states. Another limitation of Markov techniques is that Markov models are memory-less; that is, system behavior depends only on the system state and not on the way the system arrived at the state [19].

IEC 61165 uses symbols from IEC 60050 ('International Electrotechnical Vocabulary') but defines other fundamental terminology (e.g., 'up state' and 'down state'), symbols (circles, rectangles, etc.), and mathematical techniques (e.g., via ordinary differential equations and Laplace transforms) for the homogeneous Markov technique, in which the state transition rates are assumed to be timeindependent [19]. IEC 61165 shows that the differences between the expressions for reliability, maintainability, and availability arise from the different state transition diagrams used to create the equations.

\subsubsection{Petri Net Analysis}

Since their creation in 1962, Petri nets have been used to describe, design, and maintain a wide range of systems and processes in industries including aerospace, banking, manufacturing systems, and nuclear power systems [20]. Petri nets are a rigorous method to mathematically describe processes based on basic set theory [21]. Petri nets allow prototypes and processes to be tested at the earliest and cheapest design stage, thus saving time for testing and maintenance while potentially increasing reliability [20]. Furthermore, Petri nets can be used to generate the Markov models discussed in Section 2.2.2.2. Petri nets are typically used to describe complex interactions more easily than Markov models because Petri models require far fewer elements [12].

In the 1980s, Petri nets were extended to high-level Petri nets (HLPNs) to model discrete-event systems. HLPNs were also used to advance the use of Petri nets for complex systems, analogous to the use of high-level programming languages to overcome challenges with assembly languages. High-level Petri net graphs (HLPNGs) are used to model systems in a graphical form, allowing the visualization of the flow of system data and controls. Such a graphical form of HLPNs is more user-friendly for industry in that operators can visualize the data flow represented by the basic equations [20]. 
ISO/IEC 15909-1 is a standard developed by SC 7 ('Software and system engineering') of JTC 1 ('Information technology'), a Joint Technical Committee (JTC) composed of ISO and IEC members, to aid the use of HLPNs and facilitate the development of Petri net software tools [20]. Specifically, ISO/IEC 15909-1 defines a mathematical semantic model, an abstract mathematical syntax for annotations, and a graphical notation for high-level Petri nets [20]. Several levels exist for conformance to the standard, depending upon the high-level class and supporting syntax chosen by the user of ISO/IEC 15909-1.

ISO/IEC 15909-1 defines terms (such as 'arc', 'multiset', 'Petri net', 'token', 'transition', etc.) and mathematical conventions needed for high-level Petri nets and provides the formal concepts of marking, enabling, and transition rules needed for HLPNGs. As seen in Figure 10, a place (a set, a collection of objects) is graphically represented by a circle or an ellipse, while a transition (an action) is graphically represented by a rectangle in HLPNGs. Arcs (one-directional connections of nodes, of places and transitions) are represented by arrows, as seen in Figure 10 [20]. Utilizing these basic conventions, users of ISO/IEC 15909-1 can create HLPNGs that represent complex processes within manufacturing and other industries.

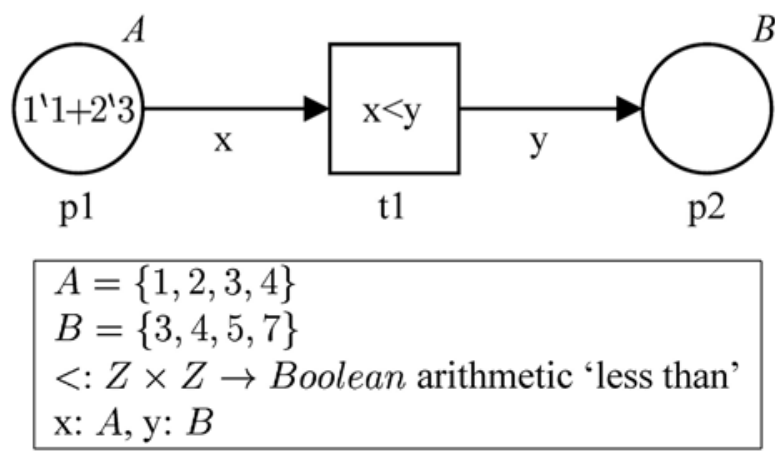

Figure 10. (Left) Graphic conventions for, and (right) an example of, high-level Petri net graphs from ISO/IEC 15909-1 [20]. [These excerpts are taken from ISO/IEC 15909-1:2004, (left) Figure D.1 on page 28 and (right) Figure 1 on page 10, with the permission of ANSI on behalf of ISO. (c) ISO 2014 - All rights reserved].

Collectively, ISO/IEC 15909 is a series of standards to support high-level Petri nets. ISO/IEC 15909-1 provides the mathematical definition of HLPNs, known as the semantic model, as well as its graphical form, HLPNGs. In a complementary manner, ISO/IEC 15909-2 defines the transfer format, the Petri Net Markup Language (PNML), to support the exchange of HLPNs [22]. The basic level of conformance to ISO/IEC 15909-2 is the use of the PNML Core Model, which is a meta model based on a unified modeling language (UML) that defines the core concepts and structure of Petri nets. The mapping of these concepts to Extensible Markup Language (XML) syntax is also covered within the standard. Furthermore, these concepts are not related to the mathematical concepts standardized in ISO/IEC 15909-1, but rather related only to the graphical representation and structure of Petri nets to ensure that the appearance of Petri nets is similar in different software. Therefore, ISO/IEC 15909-2 was written as a reference for current and future developers of Petri net tools; ISO/IEC 15909-1 is semantic in nature, covering 'types' and 'functions', while ISO/IEC 15909-2 is syntactic in nature, covering the counterparts of 'sorts' and 'operators'. 


\subsubsection{Life Cycle Costing}

As previously discussed, decisions are made during the design and manufacturing of products that affect their performance, safety, reliability, and maintainability [23]. However, those same decisions also impact, and are motivated by, the life cycle cost (LCC) of the products. LCC is the sum of the estimated price, ownership, and disposal costs. Life cycle costing (economic analysis to determine the partial or entire life cycle costs of a product) should also be applied to optimize a product's design in addition to the more technical dependability approaches. Due to the use of integrated logistics within maintenance systems, trade-off analyses during PHM deployment should include the potential improvements from inventory and labor costs.

IEC 60300-3-3 was prepared by the IEC technical committee 56 (Dependability) to address the costs associated with the dependability of products [23]. The process of life cycle costing involves the generation of a LCC model, a structure containing the mathematical expressions for the LCC costs. Accordingly, IEC 60300-3-3 contains examples of LLC models, in which the cost elements may be created by engineering, analogous, or parametric cost methods. The purpose of the analysis is to determine the cost elements whose relative contributions exceed predefined thresholds. However, the confidence of life cost costing depends on the assumptions and availability of data, so the process should be welldocumented and structured. For example, Figure 11 shows a summary of a structured breakdown of life cycle costs. Furthermore, IEC 60300-3-3 touches upon the implications of opportunity costs, inflation, and taxation on the life cycle costing process [23].

\begin{tabular}{|c|c|c|c|c|c|c|c|c|c|c|c|c|}
\hline 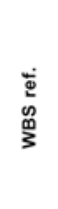 & 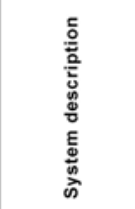 & 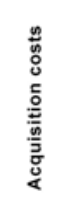 & $\begin{array}{l}\text { ò } \\
\text { कू } \\
\text { के }\end{array}$ & 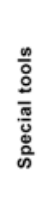 & 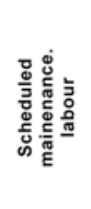 & 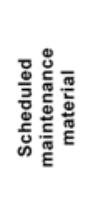 & 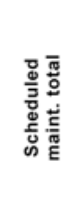 & 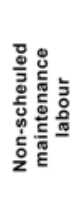 & 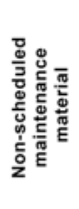 & 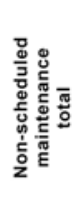 & 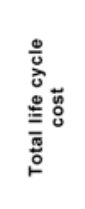 & 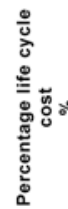 \\
\hline 1.0 & Car body & 51781 & & & 5471 & 24716 & 30187 & 208 & 4587 & 4795 & 86763 & 73 \\
\hline 2.0 & $\begin{array}{l}\text { Bogies and } \\
\text { running gear }\end{array}$ & 5820 & & & 25 & 0 & 25 & 0 & 0 & 0 & 5845 & 5 \\
\hline 3.0 & Power supply & 5811 & & & 3 & 0 & 3 & 0 & 0 & 0 & 5814 & 5 \\
\hline 4.0 & \begin{tabular}{|l|} 
Propulsion \\
\end{tabular} & 3399 & & & 2118 & 2974 & 5092 & 54 & 595 & 649 & 9140 & 8 \\
\hline 5.0 & \begin{tabular}{|l|} 
Auxiliaries \\
\end{tabular} & 1975 & & & 0 & 0 & 0 & 0 & 13 & 13 & 1988 & 2 \\
\hline 6.0 & Braking & 487 & & & 56 & 438 & 494 & 0 & 0 & 0 & 981 & 1 \\
\hline 7.0 & \begin{tabular}{|l|} 
Interiors \\
\end{tabular} & 0 & & & 0 & 0 & 0 & 0 & 0 & 0 & 0 & 0 \\
\hline 8.0 & $\begin{array}{l}\text { Control and } \\
\text { communi- } \\
\text { cation }\end{array}$ & 7151 & & & 361 & 412 & 773 & 3 & 7 & 10 & 7934 & 7 \\
\hline \multirow[t]{2}{*}{9.0} & \begin{tabular}{|l|} 
Specials \\
\end{tabular} & & & & & & & & & & & \\
\hline & Totals & 76424 & 0 & 0 & 8034 & 28540 & 36574 & 265 & 5202 & 5467 & 118465 & 100 \\
\hline
\end{tabular}

Figure 11. Life cycle cost summary by product breakdown structure from IEC 60300-3-3 [23]. [Copyright (c) 2004 IEC Geneva, Switzerland. www.iec.ch].

\subsection{Measurement Techniques}

Dependability analysis, whether top-down or bottom-up or some combination thereof, is used to identify the failure modes of the system and help manufacturers to determine which risks should be mitigated or eliminated. If a failure mode must exist, being unavoidable for system operation, then the 
failure mode may be monitored or predicted via diagnostics and prognostics with sensors and established measurement and analysis techniques. The system designer must be aware of the various measurement techniques and their preferred uses based on the accepted experience of others.

Several standards contain explicit guidelines on the use of measurement techniques for PHM. This section summarizes those particular standards indicated under the 'Measurement techniques' category within Table 1. However, due to the detailed nature and variety of measurement techniques, this document mentions these standards in a broad manner. This section mainly covers the information within these standards that are relatively general in scope and application for manufacturing.

For example, Annex B of ISO 17359 contains nine tables of guidance for measurement techniques for various systems, including generators, fans, engines, and pumps [9]. Figure 12 is one such example, showing possible faults for an electric motor and the associated measureable symptoms. For example, Figure 12 shows that the bearing unbalance affects the vibration directly, but only impacts the other detectable symptoms tangentially. Such tables are essential for understanding the basic physical consequences of system faults to aid in the selection and positioning of sensors. Similarly, Annex D of ISO 13379-1 relates measurement techniques and numerous diagnostic models in tabular form, as seen in Figure 13. The combination of the information from ISO 17359 and ISO 13379-1 helps both novices and experts in PHM to determine the measurement types and associated diagnostic techniques for a given system fault. For example, a bearing unbalance could be detected via vibration monitoring (according to Figure 12) and analyzed via a subsequent data-driven statistical method (according to Figure 13).

\begin{tabular}{|c|c|c|c|c|c|c|c|c|c|c|c|c|c|}
\hline $\begin{array}{l}\text { Machine type: } \\
\text { Electric motor }\end{array}$ & & & & & & om o & aran & er cr & & & & & \\
\hline $\begin{array}{l}\text { Examples of } \\
\text { faults }\end{array}$ & 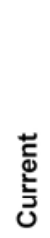 & $\begin{array}{l}\stackrel{0}{\Xi} \\
\frac{\pi}{0} \\
\text { > }\end{array}$ & 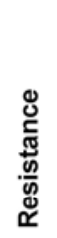 & 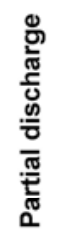 & 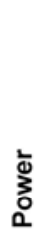 & $\begin{array}{l}\text { ㅁ } \\
\text { 흔 }\end{array}$ & 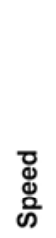 & 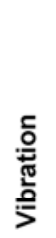 & 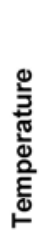 & 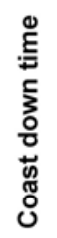 & 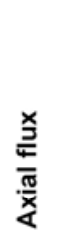 & $\begin{array}{l}\frac{0}{2} \\
\frac{0}{0} \\
\frac{0}{0} \\
0\end{array}$ & 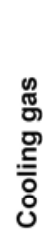 \\
\hline Rotor windings & • & & & & - & - & - & • & - & & - & & - \\
\hline Stator windings & - & & & & & & & • & • & & • & & • \\
\hline Eccentric rotor & - & & & & & & & - & & & • & & \\
\hline Brush(es) fault & - & - & & & - & - & & & - & & & & \\
\hline Bearing damage & • & & & & & - & & - & - & • & & - & \\
\hline $\begin{array}{l}\text { Insulation } \\
\text { deterioration }\end{array}$ & • & • & - & - & & & & & & & & & - \\
\hline $\begin{array}{l}\text { Loss of input power } \\
\text { phase }\end{array}$ & $\bullet$ & $\bullet$ & & & & & & • & & & - & & \\
\hline Unbalance & & & & & & & & • & & & & & \\
\hline Misalignment & & & & & & & & • & & & & & \\
\hline
\end{tabular}

Figure 12. Example of faults and their measureable symptoms from ISO 17359 [9]. [This excerpt is taken from ISO 17359:2011, Table B.2 on page 13, with the permission of ANSI on behalf of ISO. (c) ISO 2014 All rights reserved]. 


\begin{tabular}{|c|c|c|c|c|c|c|c|c|c|c|}
\hline \multirow{2}{*}{$\begin{array}{l}\text { Diagnostic } \\
\text { model/ } \\
\text { monitoring } \\
\text { technique }\end{array}$} & \multicolumn{3}{|c|}{ Knowledge-based } & \multirow[b]{2}{*}{$\begin{array}{l}\text { Statis- } \\
\text { tical } \\
\text { meth- } \\
\text { ods }\end{array}$} & \multicolumn{5}{|c|}{ Data-driven } & \multirow[b]{2}{*}{$\begin{array}{c}\text { Support } \\
\text { vector } \\
\text { ma- } \\
\text { chines }\end{array}$} \\
\hline & $\begin{array}{l}\text { Rule- } \\
\text { based }\end{array}$ & $\begin{array}{c}\text { Causal } \\
\text { fault }\end{array}$ & $\begin{array}{l}\text { First } \\
\text { prin- } \\
\text { ciple }\end{array}$ & & $\begin{array}{l}\text { Case- } \\
\text { based } \\
\text { reason- } \\
\text { ing }\end{array}$ & $\begin{array}{c}\text { Neural } \\
\text { network }\end{array}$ & $\begin{array}{l}\text { Classifi- } \\
\text { cation } \\
\text { trees }\end{array}$ & $\begin{array}{c}\text { Random } \\
\text { forest }\end{array}$ & $\begin{array}{l}\text { Logistic } \\
\text { regres- } \\
\text { sion }\end{array}$ & \\
\hline Vibration & M & D & $\mathrm{P}$ & M & D & D & - & D & - & - \\
\hline Thermography & M & - & - & $\mathrm{M}$ & - & D & - & $\mathrm{P}$ & - & - \\
\hline Oil analysis & M & $\mathrm{P}$ & - & M & D & D & - & D & D & D \\
\hline $\begin{array}{l}\text { Process } \\
\text { parameters }\end{array}$ & M & - & D & M & M & M & M & M & M & M \\
\hline Performance & M & - & D & M & $\mathrm{M}$ & M & M & M & M & $M$ \\
\hline $\begin{array}{l}\text { Acoustic } \\
\text { emission }\end{array}$ & M & - & - & M & - & D & $\mathrm{P}$ & D & - & - \\
\hline $\begin{array}{l}\text { Acoustic } \\
\text { monitoring }\end{array}$ & M & - & - & M & - & D & - & D & - & - \\
\hline $\begin{array}{l}\text { Electrical } \\
\text { monitoring }\end{array}$ & M & - & - & M & - & D & - & - & - & - \\
\hline $\begin{array}{l}\text { M: Mature and } \\
\text { D: Under develc } \\
\text { P: Promising an }\end{array}$ & $\begin{array}{l}\text { mmonly a } \\
\text { ment and } \\
\text { potential. }\end{array}$ & plied in in & trial ap & ations. & & & & & & \\
\hline
\end{tabular}

Figure 13. Measurement techniques for various diagnostics models from ISO 13379-1 [24]. [This excerpt is taken from ISO 13379-1:2012, Annex D on page 26, with the permission of ANSI on behalf of ISO. (c) ISO 2014 - All rights reserved].

As seen in Table 1, other standards are more specific in their guidance for the use of numerous measurement techniques: ISO 13373-1 and ISO 13373-2 are useful for vibration monitoring, ISO 18434-1 for thermography, ISO 20958 for analysis of electrical motor signatures, ISO 22096 for acoustic emission monitoring, and ISO 29821-1 for ultrasound monitoring. These standards guide the application of sensors based on conditions such as data requirements and analysis techniques. This document mentions these standards for thoroughness and recommends that these standards be utilized, when applicable, for the development of measurement techniques used within PHM systems.

\subsection{Diagnostics and Prognostics}

Diagnostics is the determination of the current condition of a component or system, and prognostics is the predictive ability of future performance degradation and expected failures [25]. Both diagnostics and prognostics require data collection and analysis to enable decision making by system managers. Accordingly, the standards described in the previous sections about dependability analyses ('why' and 'what' to measure) and measurement techniques ('how' to measure) enable the measurements used for diagnostics and prognostics, which support decisions that reduce costs, improve safety, and optimize maintenance scheduling. The entire process of machine condition monitoring can be categorized into five distinct phases: problem detection, diagnostics, prognostics, recommendation of actions, and postmortems [26].

The following subsections summarize those particular standards indicated under the 'Diagnostics and Prognostics' category within Table 1 . As seen in the table, the number of existing standards with general focuses on diagnostics and prognostics is fairly limited; this section is fairly short yet comprehensive. 


\subsubsection{Diagnostics}

One recently-published standard aids the diagnostics of general PHM processes; ISO 13379-1 was created to aid the condition monitoring of industrial machines including turbines, compressors, pumps, generators, electrical motors, blowers, gearboxes, and fans [24]. ISO 13379-1, which was prepared under SC 5 (Condition monitoring and diagnostics of machines) of ISO/TC 108 (Mechanical vibration, shock and condition monitoring), outlines the condition monitoring and diagnostics cycle into a preparatory design phase and a usage phase. As mentioned in Section 2.3, the standard addresses the connection of measurement techniques to diagnostic approaches [24]. However, ISO 13379-1 mainly outlines the nine generic steps for diagnostics, of which the first four (steps 1 to 4 ) are satisfied by FMEA or FMECA as outlined in IEC 60812. The last seven steps (steps 3 to 9) are followed using the FMSA (failure mode symptoms analysis) methodology outlined in ISO 13379-1, which is essentially a modification of a FMECA process that focuses on the selection of the most appropriate detection and monitoring techniques and strategies. The process results in a monitoring priority number (MPN) for each failure mode. The MPN is the product of four numbers representing the confidence (each rated from 1 to 5) of detection, severity, diagnosis, and prognosis for the given failure mode. The highest MPN value indicates the most suitable technique for detection, diagnostics, and prognostics of the associated failure mode [24].

ISO 13379-1 also outlines the data-driven diagnostic approaches (e.g., neural network, logistic regression, and support vector machine) and the knowledge-based diagnostic approaches (e.g., causal tree and first principles), comparing their strengths and weaknesses, as seen in Figure 14. Based on such a comparison, Figure 15 shows a convenient flow chart for choosing a diagnostic model. The decision is based on the model type, whether knowledge-based or data-driven, and the relative strength of the information. The last step in the diagnostic process is a formal diagnostic report, such as an example given in Annex E of ISO 13379-1, which includes information about the event, its diagnosis, symptoms, failure modes, and recommendations for corrective action and fault avoidance. 
This publication is available free of charge from http://dx.doi.org/10.6028/NIST.IR. 8012

\begin{tabular}{|c|c|c|c|c|}
\hline $\begin{array}{l}\text { Diagnostic } \\
\text { method }\end{array}$ & Knowledge used & Strong points & Weak points & $\begin{array}{l}\text { Typical applications } \\
\text { and references }\end{array}$ \\
\hline Rule-based & Human expertise & $\begin{array}{l}\text { - Relatively simple to } \\
\text { implement }\end{array}$ & $\begin{array}{l}\text { - Incompleteness } \\
\text { - Difficulty in explaining } \\
\text { multiple faults } \\
\text { - Poor explicative } \\
\text { capacity } \\
\text { - Brittleness to system } \\
\text { changes }\end{array}$ & $\begin{array}{l}\text { - Rotating machinery } \\
\text { diagnosis } \\
\text { - Medical diagnosis }\end{array}$ \\
\hline Causal fault & $\begin{array}{l}\text { Description of fault } \\
\text { mechanism and } \\
\text { propagation }\end{array}$ & $\begin{array}{c}\text { - Explicative diagnosis } \\
\text { - Handling of multiple } \\
\text { independent faults }\end{array}$ & $\begin{array}{l}\text { - Requires good } \\
\text { knowledge of possible } \\
\text { faults (tested } \\
\text { equipment) } \\
\text { — Incomplete } \\
\end{array}$ & $\begin{array}{l}\text { - Rotating machinery } \\
\text { diagnosis } \\
\text { - Medical diagnosis }\end{array}$ \\
\hline First principles & $\begin{array}{l}\text { Decomposition and } \\
\text { transfer function of } \\
\text { equipment }\end{array}$ & $\begin{array}{l}\text { - Does not require } \\
\text { knowledge of faults } \\
\text { (new equipment) } \\
\text { - Handles multiple faults } \\
\text { well } \\
\text { - Gives flexibility to } \\
\text { system modification, } \\
\text { FMEA, test generation, } \\
\text { diagnosis analysis }\end{array}$ & $\begin{array}{l}\text { - Non-explicative } \\
\text { diagnosis } \\
\text { - Possible aberrant } \\
\text { diagnosis } \\
\text { - Model complexity } \\
\text { in certain domains }\end{array}$ & $\begin{array}{l}\text { - Electronic or fluid } \\
\text { circuit diagnosis } \\
\text { - Automotive engines } \\
\text { and control systems }\end{array}$ \\
\hline $\begin{array}{l}\text { Statistical } \\
\text { Case-based } \\
\text { reasoning }\end{array}$ & $\begin{array}{l}\text { Samples of significant } \\
\text { past diagnosis cases }\end{array}$ & $\begin{array}{l}\text { - Approach well } \\
\text { understood } \\
\text { - Does not require } \\
\text { in-depth knowledge } \\
\text { of dysfunctions }\end{array}$ & $\begin{array}{l}\text { - Difficulty in obtaining } \\
\text { a sufficient number } \\
\text { of significant, well- } \\
\text { described cases }\end{array}$ & $\begin{array}{c}\text { - Aeroplane engine } \\
\text { diagnosis }\end{array}$ \\
\hline $\begin{array}{l}\begin{array}{l}\text { Classification } \\
\text { trees }\end{array} \\
\text { Random forests } \\
\text { (RFs) } \\
\text { Logistic } \\
\text { regression (LR) } \\
\text { Neural networks } \\
\text { Support vector } \\
\text { machines } \\
\text { (SVMs) }\end{array}$ & $\begin{array}{l}\text { Samples of significant } \\
\text { past diagnosis cases } \\
\text { and associated data }\end{array}$ & $\begin{array}{l}\text { - Does not require } \\
\text { in-depth knowledge } \\
\text { of dysfunctions } \\
\text { - RF can accommodate } \\
\text { missing data }\end{array}$ & $\begin{array}{l}\text { - Non-explicative } \\
\text { diagnosis } \\
\text { - Difficulty in obtaining } \\
\text { a sufficient number } \\
\text { of significant, well- } \\
\text { described cases }\end{array}$ & - Any application \\
\hline
\end{tabular}

Figure 14. Comparison of diagnostic models from ISO 13379-1 [24]. [This excerpt is taken from ISO 13379-1:2012, Annex C on page 25, with the permission of ANSI on behalf of ISO. (c) ISO 2014 - All rights reserved]. 


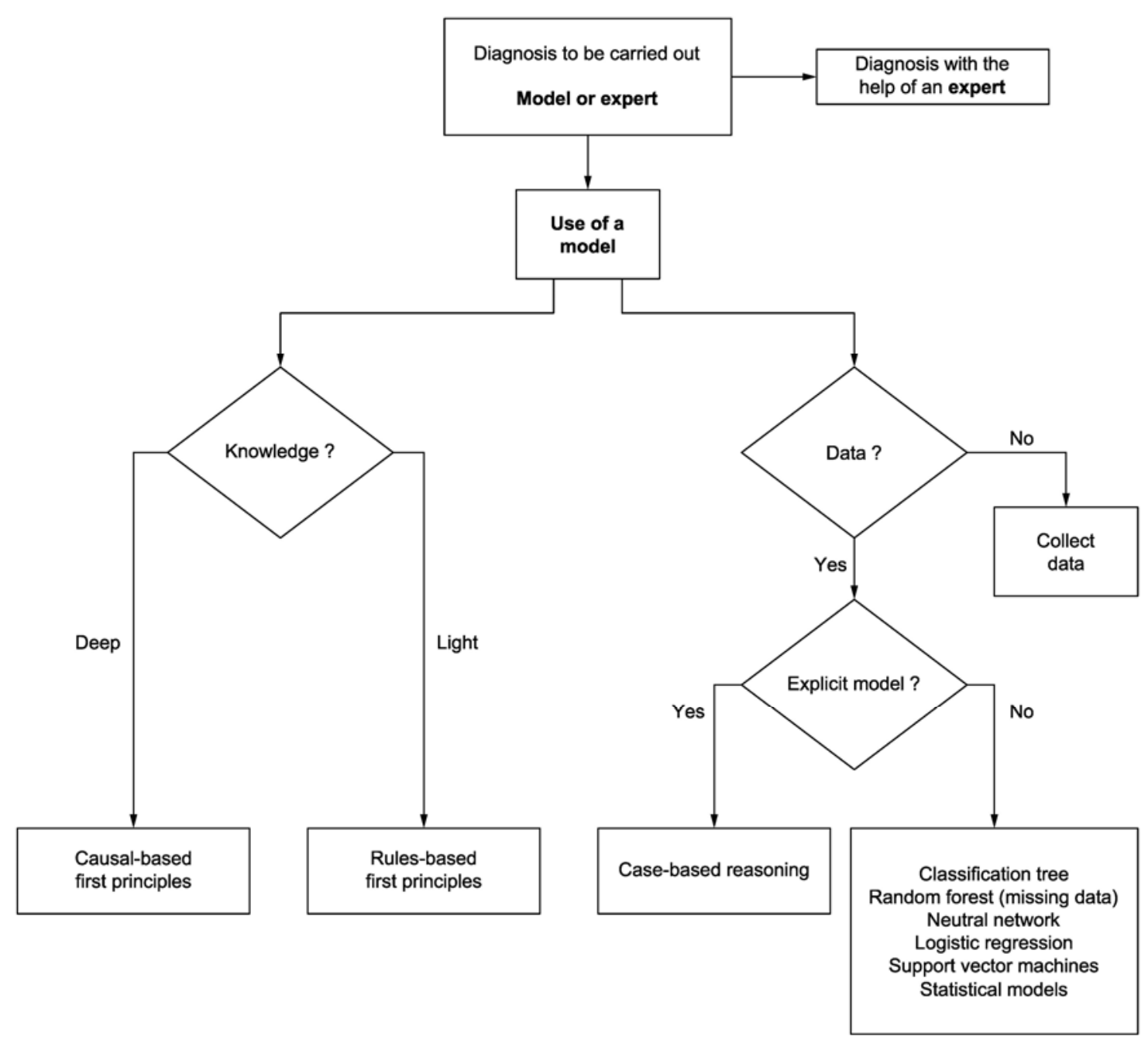

Figure 15. Diagnostic model decision flowchart from ISO 13379-1 [24]. [This excerpt is taken from ISO 13379-1:2012, Figure 2 on page 10, with the permission of ANSI on behalf of ISO. (c) ISO 2014 - All rights reserved].

\subsubsection{Prognostics}

Other standards are needed to provide guidance for prognostics, because there is currently no precise procedure or standard methodology. Fault prognostics require prior knowledge of the probable failure modes, the anticipated future activities of the machine, and the relationships between failure modes and operating conditions [26]. Because prognostics are focused on future predictions, the prognosis needs to consider future failure modes, operating conditions, and maintenance actions. These requirements are not necessarily obvious because such information may be based on experience or difficult to predict or quantify. As analytical damage models are introduced and computing power increases, the ability to predict faults is conceivable if the set of parameter values that represent initiation criteria are known for a given set of conditions [26]. 
To facilitate the development of prognostics within general PHM processes, ISO 13381-1 outlines general guidelines, approaches, and concepts for prognostics [26]. ISO 13381-1 uses ISO 13372 [27] ('Condition monitoring and diagnostics of machines - Vocabulary') and ISO 17359 (see Section 2.1) as normative references. Also, terms such as prognosis (an estimation of time to failure and associated risk), confidence level, root cause, and estimated time to failure (ETTF) are defined in ISO 13381-1.

ISO 13381-1 also outlines the four basic phases of prognosis: pre-processing, existing failure mode prognosis, future failure mode prognosis, and post-action prognosis. ISO 13381-1 states that the trip set point used for thresholding to prevent damage or failure is a parameter value, normally determined from standards, manufacturers' guidelines, and experience. Other thresholds, such as alert and alarm limits, are set at values below the trip set point to initiate maintenance. Once a fault has been detected based on a failure mode behavior model (FMECA, FTA, etc.), the estimated time to failure (ETTF) needs to be determined by expert opinion and/or empirical methods [26].

\subsection{Data Management}

Monitoring the condition of machines is not an easy task because the integration of various PHM software is typically not 'plug-and-play' [28]. Dependability data must be collected, processed, and managed for diagnostic and prognostic purposes of the given system. Ideally, the raw data, its processed forms, and dependability decisions, based on the data, would be stored in a fashion presentable in support of various activities (e.g., data mining purposes for the advancement of PHM in other systems). Consequently, several standards exist for the purpose of guiding the management of PHM data and, hence, the integration of various PHM software via the transfer of standardized data formats. This section summarizes those particular standards indicated under the 'Data management' category within Table 1.

ISO 13374-1 was created by ISO/TC 108/SC 5 to provide the basic requirements for open software specifications to facilitate the transfer of data among various condition monitoring software, regardless of platform or hardware protocols [28]. ISO 13374-1 establishes the general guidelines, while later parts of ISO 13374 address the specific software requirements for data processing, communication, and processing. One of these general guidelines is the requirement of an 'open machine condition monitoring information schema architecture as an underlying framework' [28]. Vendor-independent XML schema and protocols can be used for the network exchange of PHM information. In accordance with ISO 13374, the Machinery Information Management Open Systems Alliance (MIMOSA) published a conceptual schema called the Common Relational Information Schema (CRIS) in Adobe PDF, Microsoft Word, and XML schema forms. The CRIS has been used in the condition monitoring industry to communicate and integrate information from many systems [29]. Ultimately, to facilitate maintenance decisions by qualified personnel, information would be displayed through use of machine identification, recommended actions, prognosis, health assessment, and pertinent data, as seen in Figure 16. 


\begin{tabular}{|c|c|c|}
\hline \multicolumn{3}{|c|}{$\begin{array}{l}\text { Identification } \\
\text { dipment ID: Engine B } \\
\text { Date: } 2001-06-03 \\
\text { Time: } 14: 51 \text { UTC }\end{array}$} \\
\hline Area 4 & $\begin{array}{r}\operatorname{Rec} \\
1)\end{array}$ & ctions \\
\hline Area 3 & A) $\mathrm{E}$ & $\begin{array}{l}88 \mathrm{~h} \\
\text { oil change }\end{array}$ \\
\hline Area 2 & $\begin{array}{r}\text { He } \\
\text { Health index } \\
2 \text { [Best = 10] }\end{array}$ & $\begin{array}{l}\text { ent } \\
\text { Diagnosed problems } \\
\text { Severe bearing spalling }\end{array}$ \\
\hline Area 1 & 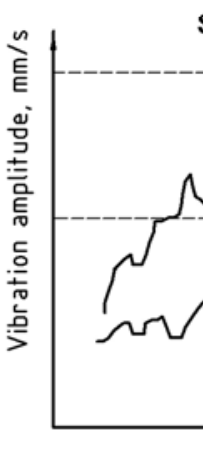 & $\begin{array}{l}\text { n } \\
\text { ft thrust bearing } \\
\text { ion bearing }\end{array}$ \\
\hline
\end{tabular}

Figure 16. Example of an aircraft engine display for condition monitoring from ISO 13374-1 [28]. [This excerpt is taken from ISO 13374-1:2003, Figure 3 on page 12, with the permission of ANSI on behalf of ISO. (c) ISO 2014 - All rights reserved].

ISO 13374-2 provides requirements for a reference information model and a reference processing model for an open condition monitoring and diagnostics (CM\&D) architecture [30]. In other words, ISO 13374-2 provides details of the methodology and requirements for data processing within CM\&D systems. ISO 13374-2 describes the required content for the five layers (1 - semantic definitions, 2 - a nonproprietary conceptual information model or 'schema', 3 - implementation data model, 4 - reference data library, and 5 - data document definitions) of the open CM\&D information architecture, which describes all the data objects, types, relationships, etc. for a given system [30]. Finally, ISO 13374-2 provides an informative annex about the UML, XML, and Middleware services.

MIMOSA publishes an open CM\&D information specification known as the MIMOSA Open Systems Architecture for Enterprise Application Integration (OSA-EAI ${ }^{\mathrm{TM}}$ ), which is compliant with the requirements outlined in ISO 13374-1 and ISO 13374-2 and free for download [31]. Such an open CM\&D 
processing architecture specification uses the processing architecture seen in Figure 17. This processing architecture processes and transforms basic data into actionable information. ISO 13374-2 details the input and outputs of each of the six processing blocks from Data Acquisition (DA) to Advisory Generation (AG). MIMOSA also publishes an open CM\&D specification known as the MIMOSA Open Systems Architecture for Condition Based Maintenance (OSA-CBM ${ }^{\mathrm{TM}}$ ), which is based on OSA-EAI ${ }^{\mathrm{TM}}$ as well as on ISO/IEC 14750 for the processing blocks, enabling integration of systems from various suppliers [30]. The MIMOSA interface standard does not impose a structure on the components that comprise a MIMOSA compliant system. This lack of structure allows complete encapsulation of proprietary algorithms and software, and is a key enabler to prognostic module implementation [32]. Furthermore, MIMOSA developed various whitepapers, including one on the condition of CBM [33] and another on conditionbased operations for manufacturing [34].

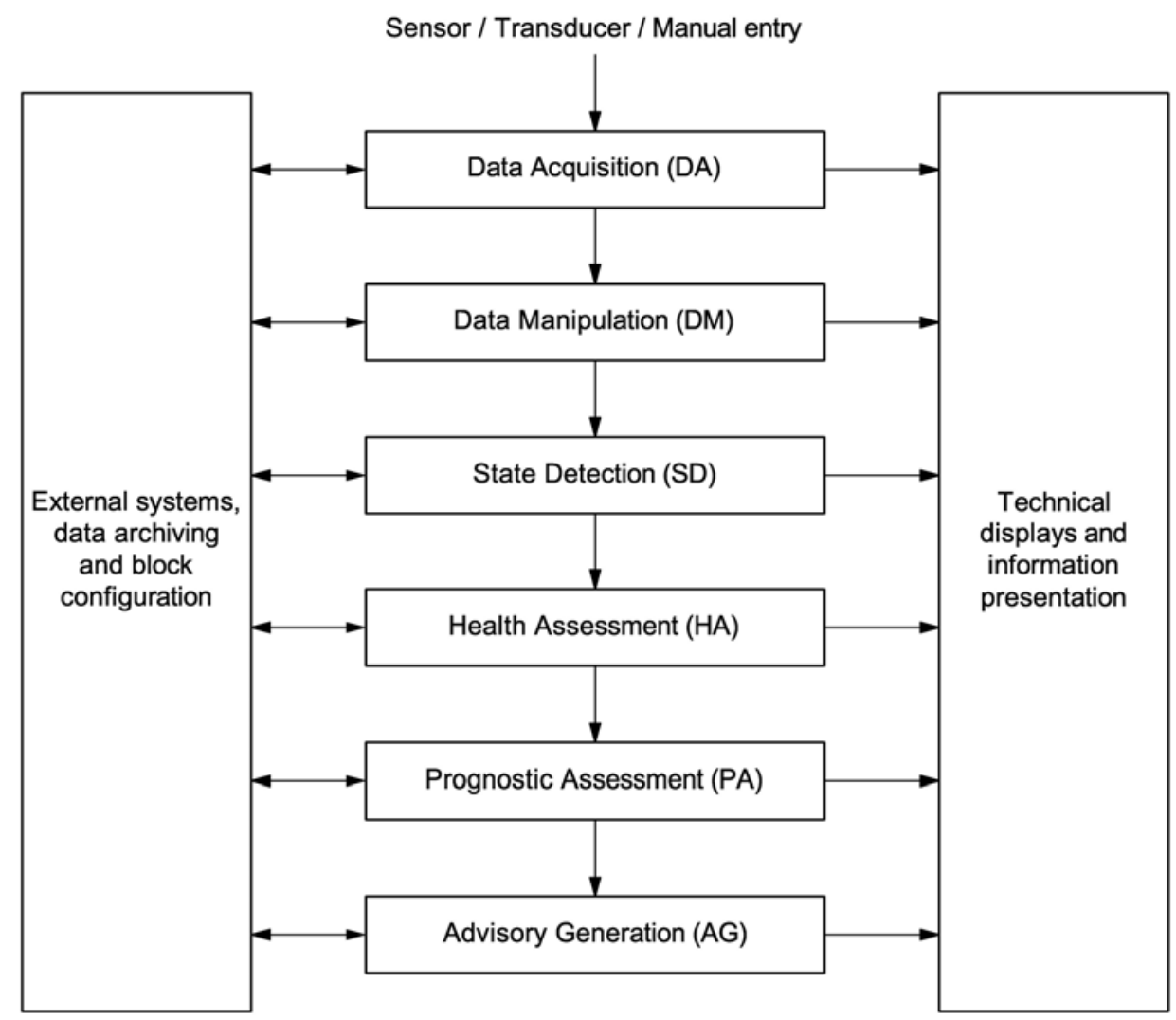

Figure 17. Data processing block diagram for open CM\&D information architecture from ISO 133742 [30]. [This excerpt is taken from ISO 13374-2:2007, Figure 2 on page 5, with the permission of ANSI on behalf of ISO. (c) ISO 2014 - All rights reserved].

The third part of ISO 13374, ISO 13374-3, defines the communication requirements for any open CM\&D systems to aid the interoperability of such systems [35]. The technologies and software used by the data-oriented processing blocks (DA, DM, and SD) often vary from those used by the analysis-oriented processing blocks (HA, PA, and AG) seen in Figure 17. ISO 13374-3 states that a UML model, compliant with ISO/IEC 19501, shall support the open CM\&D data-processing communications. ISO 13374-3 defines the block processing methods and interface types that should be utilized by each dataprocessing block defined in ISO 13374-2. Also, based on IEC/DIS 62264-5, ISO 13374-3 contains an 
informative annex of an open CM\&D information architecture with the message structure seen in Figure 18.

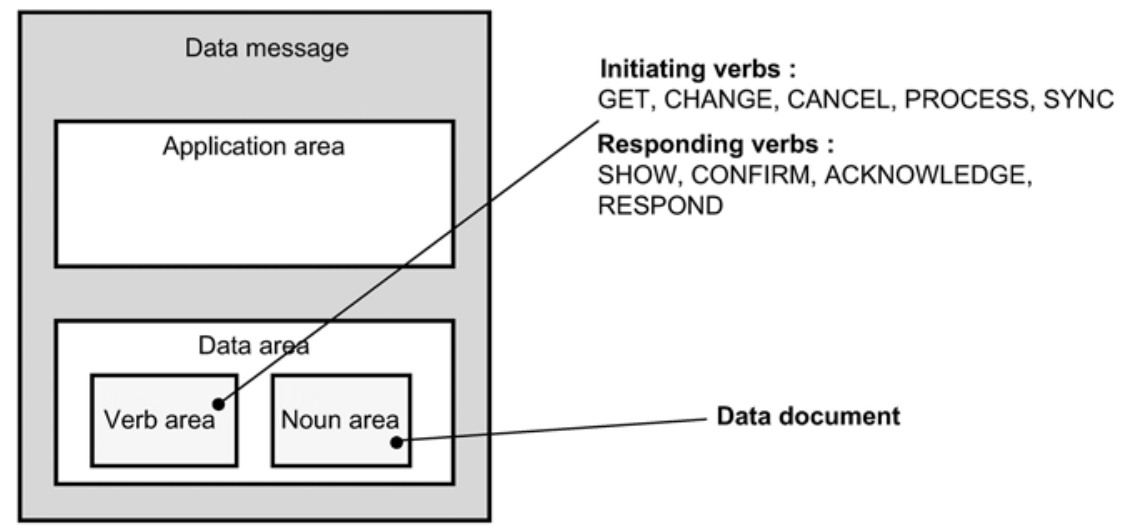

Figure 18. Message structure, compliant with IEC/DIS 62264-5, from ISO 13374-3 [35]. [Grayscale version. This excerpt is taken from ISO 13374-3:2012, Figure A.1 on page 10, with the permission of ANSI on behalf of ISO. (c) ISO 2014 - All rights reserved].

The ISO 13374 standard series applies to systems including process plants, and the cross-organizational nature of the plant information necessitates a robust data management structure with efficient integration. Accordingly, information related to the engineering, construction, and operation of process plants must be managed and utilized by owners, operators, contractors, and regulators during the life of a plant [36]. These process plants operate in various industries, including oil and gas, power generation, chemical manufacturing, pharmaceuticals, and food. In order to facilitate the integration of process plant life-cycle data, ISO 15926-1 [36] was prepared by ISO/TC 184/SC 4 for the representation of process plant life-cycle information via a data model with consistent context for data definitions. ISO 15926 complements other standards for industrial data management, including ISO 10303-11 that specifies the 'EXPRESS' data modeling language for product data representation and exchange [37].

The information architecture outlined in ISO 15926-1 is seen in Figure 19 and was designed such that conceptual and reference data may be represented concisely without the need for duplication. ISO 15926-2 [38] specifies a conceptual data model used within the architecture outlined in Figure 19. An information system conforming to this architecture should provide an application programming interface (API) with operations following the guidance in ISO 15926-1.

Other standards apply to data management needs within manufacturing enterprises. In a manufacturing enterprise, a properly integrated asset management system should provide critical information to improve the productivity of the existing manufacturing assets, which is increasingly possible as digital signal processing has become more mature. The main focus of the ISO 18435 standards series is to describe the integration requirements that manufacturing assets and resources need to support operations and maintenance within a manufacturing system's lifecycle, as seen in Figure 20 [39]. In ISO 18435, the functions and interfaces that gather information about process, equipment, operators, materials, etc. (related to various diagnostics for asset management) are based on the definitions and concepts from other standards, such as IEC 62264, ISO 15745, ISO 13374, MIMOSA OSA-CBM, and MIMOSA OSA-EAI [39]. By utilizing the general tools outlined in ISO 18435, system integrators can reduce the time to develop diagnostics and maintenance solutions. Use of ISO 18435 will help manufacturers to realize optimized performance, costs, safety, and environmental compatibility [39]. 


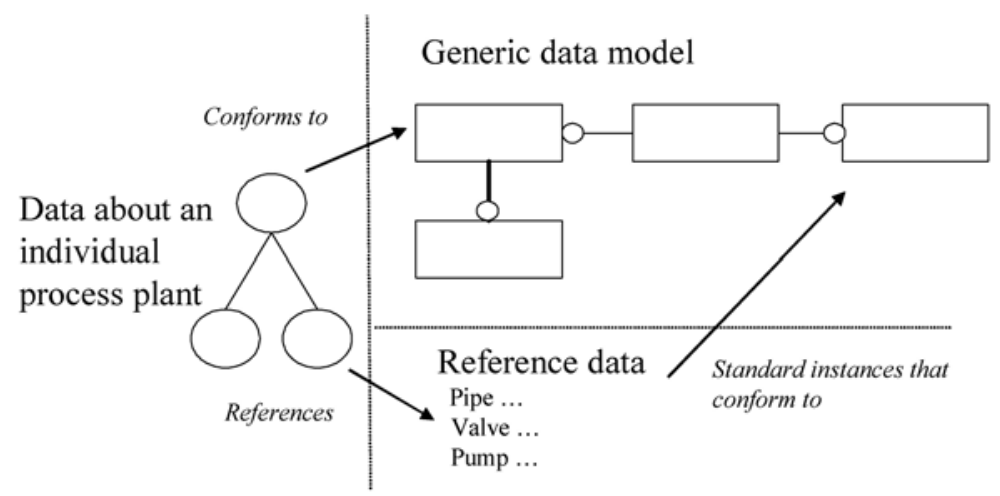

Figure 19. Information architecture from ISO 15926-1:2004 [36]. [This excerpt is taken from ISO 159261:2004, Figure 2 on page 7, with the permission of ANSI on behalf of ISO. (c) ISO 2014 - All rights reserved].

\begin{tabular}{|c|c|c|c|c|c|}
\hline Design & Implementation & Commissioning & & $\begin{array}{l}\text { tions (e.g. } \\
\text { \& Maintenance) }\end{array}$ & End of Life \\
\hline \multicolumn{6}{|c|}{ Manufacturing System Life Cycle } \\
\hline ISO10303 & \multicolumn{3}{|c|}{$\begin{array}{l}\text { Other standards (e.g } \\
\text { IEC 62264, ISO 13374) }\end{array}$} & ISO 18435 & $\begin{array}{c}\text { Other } \\
\text { standards }\end{array}$ \\
\hline
\end{tabular}

Figure 20. Scope of ISO 18435 in the lifecycle of a manufacturing system from ISO 18435-1 [39]. [This excerpt is taken from ISO 18435-1:2009, Figure 1 on page vi, with the permission of ANSI on behalf of ISO. (c) ISO 2014 - All rights reserved].

ISO 18435-1 gives an overview of the elements and rules of an integration modeling method to describe a manufacturing application's requirements for integration of an automation application with other applications, e.g., diagnostics, prognostics, capability assessment, and maintenance applications with production and control applications [39]. The method is based upon the Application Domain Integration Diagram (ADID), as seen in Figure 21, which facilitates the transfer of information among various application domains of the manufacturing process. The domains involve the integration of information including the processing blocks of ISO 13374, such as the Data Monitoring block or the State Detection block. ISO 18435-1 defines terms (e.g., 'integration' and 'interaction') and provides examples of exchanged information among domains (e.g., see Figure 22). 


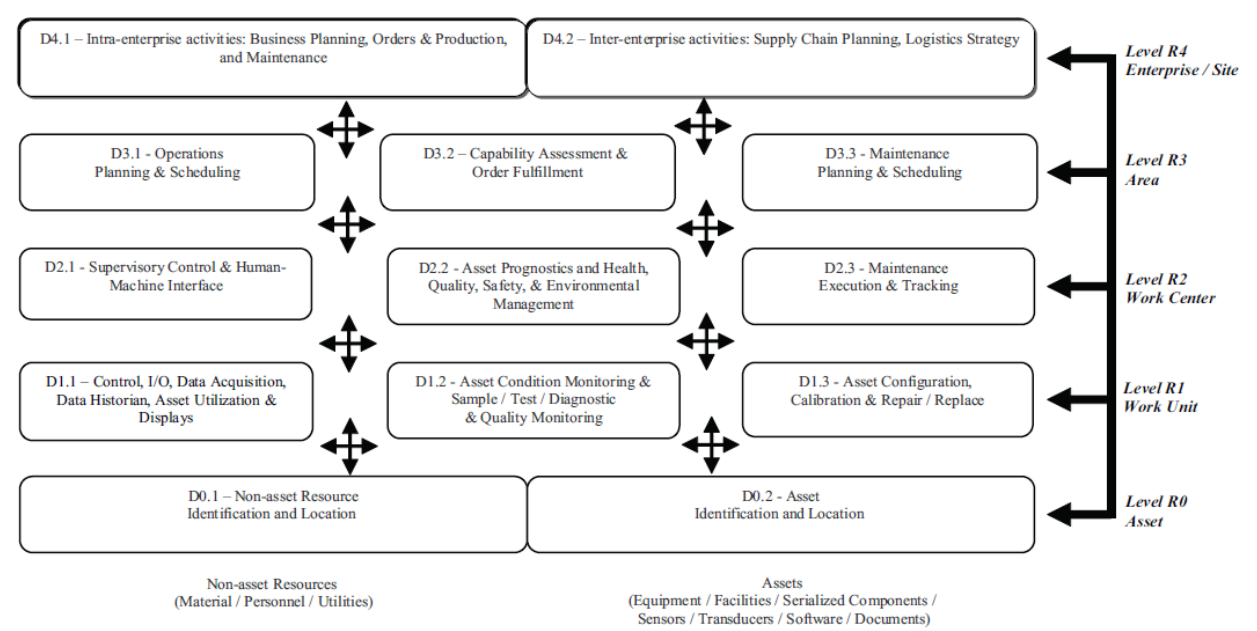

Figure 21. Application Domain Integration Diagram from ISO 18435-1 [39]. [This excerpt is taken from ISO 18435-1:2009, Figure 5 on page 7, with the permission of ANSI on behalf of ISO. (c) ISO 2014 - All rights reserved].

\begin{tabular}{|c|c|c|c|c|}
\hline & \multicolumn{3}{|c|}{ To } \\
\hline & & D1.1 & D1.2 & D1.3 \\
\hline \multirow{3}{*}{ From } & D2.1 & $\begin{array}{l}\text { - Supervisory control } \\
\text { instructions } \\
- \text { 1/O instructions }\end{array}$ & $\begin{array}{l}\text { Desired condition monitoring data } \\
\text { and abnormality events }\end{array}$ & $\begin{array}{l}\text { Manual request to change } \\
\text { configuration for a different } \\
\text { product recipe }\end{array}$ \\
\hline & D2.2 & \begin{tabular}{|l} 
- \\
Desired operational data \\
(polled or pushed) \\
- Desired operational alarm \\
and events (polled or \\
pushed)
\end{tabular} & $\begin{array}{l}\text { - Abnormal state profiles } \\
\text { - Condition monitoring } \\
\text { locations and frequency }\end{array}$ & $\begin{array}{l}\text { Recalibration request for different } \\
\text { grade of product to be made }\end{array}$ \\
\hline & D2.3 & $\begin{array}{l}\text { Desired operational data and } \\
\text { push frequency to trigger } \\
\text { Preventive Maintenance }\end{array}$ & $\begin{array}{l}\text { Desired diagnostic data and push } \\
\text { frequency to trigger Preventive } \\
\text { Maintenance }\end{array}$ & $\begin{array}{l}\text { - } \text { CBM work request/work order } \\
\text { tracking data } \\
\text { - PM work request for } \\
\text { calibration/configuration }\end{array}$ \\
\hline
\end{tabular}

Figure 22. Items exchanged from domains at Level 2 to domains at Level 1 from ISO 18435-1 [39]. [This excerpt is taken from ISO 18435-1:2009, Table A.6 on page 18, with the permission of ANSI on behalf of ISO. (c) ISO 2014 - All rights reserved].

ISO 18435-2 helps to enable the interoperability of manufacturing resources, which can achieve compatibility among interfaces via ISO 15745 templates. This interoperability results in an integrated system for the flow of material, information, and energy, which is needed for diagnostic and prognostic processes within PHM systems. ISO 18435-2 defines the application interaction matrix element (AIME) and application domain matrix element (ADME) structures and relationships, including the steps to construct an ADME for support by a set of AIMEs [40]. An AIME represents a set of capabilities provided by a set of manufacturing resources of an application. An ADME is a means to model the information exchanges between applications, being constructed from interoperability profiles referenced in AIMEs. For example, Figure 23 shows an ADME linking two conceptual AIMEs. ISO 18435-2 outlines the XML schema for the headers and bodies that comprise AIMEs and ADMEs. AIME bodies consist of context and conveyance sections, and ADME bodies consist of context, conveyance, and content sections. Figure 24 shows an example of the attributes, but ISO 18435-2 also contains formal definitions of the ADME/AIME schemas in informative annexes [40]. 


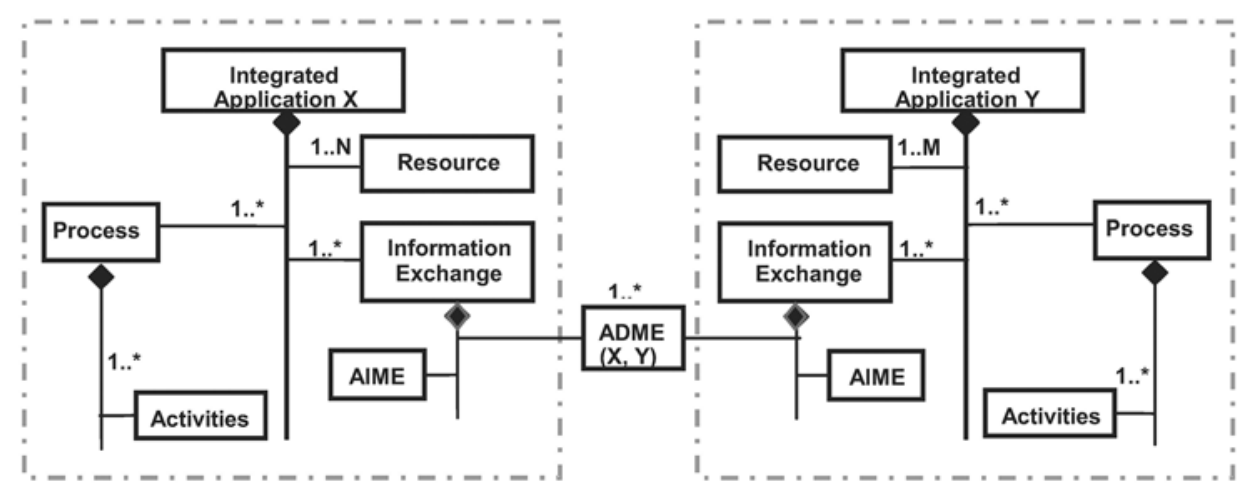

Figure 23. Interoperability of applications from ISO 18435-2 [40]. [This excerpt is taken from ISO 184352:2012, Figure 4 on page 3, with the permission of ANSI on behalf of ISO. (c) ISO 2014 - All rights reserved].

\begin{tabular}{|l|l|l|}
\hline \multicolumn{1}{|c|}{ Attribute } & \multicolumn{1}{c|}{ Description } & \multicolumn{1}{c|}{ Example } \\
\hline MEidentification & AIME identification & ISO_AIME \\
\hline MErevision & Revision of the AIME & V01.01.01a \\
\hline MEname & Descriptive name of the AIME & D.2.2.Ay_D.2.2Az \\
\hline MEsource & Identification of the AIME developer & AIMEsrc \\
\hline MEclassID & Identification of the AIME class & AIP \\
\hline MEdate & $\begin{array}{l}\text { The release data of this version of the } \\
\text { AIME }\end{array}$ & 2007-03-29 \\
\hline MEregistry & Registry name for this AIME & Industry_specific_registry_name \\
\hline
\end{tabular}

Figure 24. AIME template header attributes from ISO 18435-2 [40]. [This excerpt is taken from ISO 18435-2:2012, Table 1 on page 5, with the permission of ANSI on behalf of ISO. (c) ISO 2014 - All rights reserved].

Other industrial data management standards can be broadly applied to PHM systems. IEEE 1232-2010 (AI-ESTATE) is utilized for data exchange in test and diagnostic environments [41], and ISO 1553144:2010 provides data models for use by any software to manage and improve manufacturing [42]. ISO 15531-44:2010 addresses the modeling of data (quantitative or qualitative) collected from data acquisition systems at the control level (level 2 of IEC 62264-1) to be stored at the manufacturing management level (level 3 of IEC 62264-1) and processed further at this level for any management purpose. The standard provides data models that are able to be used by any software to manage and improve manufacturing. Normative references include other parts of ISO 15531 (parts 1, 31, 32, 42, and 43), ISO 10303-11, ISO 13584-1, and ISO 13584-24.

\subsection{Training}

Before the implementation of PHM systems, personnel should be trained to use such systems, and certain standards guide the requirements needed for training processes. Specifically, ISO 18436 includes requirements for the qualification and assessment of personnel for condition monitoring and diagnostics systems for machines [43]. The series covers general requirements and guidance for training related to measurements of vibration (part 2), field lubricants (parts 4 and 5), acoustic emission (part 6), thermography (part 7), and ultrasound (part 8). This document does not focus on these training-related standards since the emphasis of this standards survey is on PHM system development, methodologies and metrics. 


\subsection{Applications}

The previous sections describing the elements of PHM system development and implementation may be applied to various manufacturing products and processes. The standards mentioned in this document are organized fairly independently of industry, in order to reveal any common ground among existing standards while inspiring the usage of standards across disciplines. Certain standards contain significant guidance for PHM systems within only specific industries, as indicated under the 'Applications' category within Table 1.

\subsubsection{Aerospace Industry}

The Society of Automotive Engineers (SAE) is a U.S.-based association for engineering professionals in various industries, particularly transportation (automotive, aircraft, etc.). SAE has developed thousands of Aerospace Standards including Aerospace Information Reports (AIRs) and Aerospace Recommended Practices (ARPs). AIRs and ARPs are documents that give dimensional design or performance recommendations for standard engineering practices [44]. Some of these documents provide guidance for PHM systems of aircraft and their components.

One vital component to monitor is the aircraft engine. Engine health management (EHM) is defined as the "general discipline or techniques for detection, accommodation, diagnosis and prognosis of degradation or failure of an engine system, piece of equipment, component or subassembly and offering a maintenance action or decision support to address the degradation" [45]. EHM systems are part of an integrated vehicle health management (IVHM) system. If EHM can provide sufficient prognostics, then maintenance support can tailor their efforts to reduce the logistic footprint. EHM generally includes warning systems in order to mitigate failures during the 'fault to failure progression', but future systems might include anomaly detection and advanced monitoring and analysis for vibration, turbine blade performance, and oil health [45].

Because EHM is becoming more important for optimizing aircraft utilization, SAE ARP1587B was written as a guide for aircraft gas turbine EHM for use by commercial and government operators, aircraft manufacturers, engine producers, and equipment suppliers. Under the E-32 Aerospace Propulsion Systems Health Management Technical Committee, SAE ARP1587 was introduced in 1981 and revised as version $A$ in 1993. This standard was further revised as version B in 2007, which was subsequently reaffirmed in 2013 [46]. SAE ARP1587B gives a top-level view of Engine Health Management (EHM), addressing benefits and capabilities while providing examples and possible design options. SAE ARP1587B describes EHM terminology (e.g., 'failure', 'fault', and 'life') and the four essential elements of an EHM system (symptomatics, diagnostics, prognostics, and prescriptive action). Because prescriptive action can be taken at different levels, SAE ARP1587B separates prognostics into three predictions based upon time scale: 'near-horizon prognostics' (up to two weeks), 'mid-horizon prognostics' (between two weeks and two months), and 'far-horizon prognostics' (greater than two months). Other referenced SAE documents provide detailed implementation steps and procedures for EHM.

EHM is basically an information exchange process that supports the prescriptive action decisions made by engine maintenance and design personnel for improved reliability, logistics, efficiency, costs, and 
safety [45]. An EHM system should be reliable, valid (see SAE AIR5120 for guidance), and continuously improved and upgraded. However, retrofitting an EHM sensor on an in-service aircraft is usually too costly compared to its benefits (see SAE AIR4176 for cost/benefit analysis guidance) [45]. Nonetheless, advancements in technology and computation capabilities are making automation of EHM more costeffective for new designs. Current EHM concerns include system architecture, data/information interfaces, system integration, data security, and regulatory requirements [45].

Health management for military aircraft is improving due to advances in sensors (for detecting oil debris, vibration, etc.), model-based PHM (on-board models for real-time health estimation), and logistics (e.g., real-time data exchange). The Joint Strike Fighter (F-35) is such an example, because it is built around on-board failure diagnostics and prognostics with real-time communication to the logistics infrastructure for immediate corrective action [45]. Therefore, when an F-35 returns from a mission, it may be met at the airfield with needed maintenance for an efficient turnaround, serving the ultimate goal of PHM (delivering true condition-based maintenance capability) [45].

The increasing interest in gas turbine prognostics led to SAE AIR5871, which addresses the foundation of prognostics for engine health monitoring [25]. Prognosis depends on fault isolation and diagnosis, and as such, SAE AIR5871 delineates prognostics between condition prognostics (to forecast remaining useful life based on identified degradation) and failure prognostics (if the identified fault affects component life) [25]. SAE AIR5871 summarizes the five leading data-driven and model-based analytical approaches: 1 - experience-based prognostics (simplest approach that uses failure or inspection data), 2 evolutionary prognostics (works well for system level degradation), 3 - feature progression and Al-based prognostics (includes trained neural networks), 4 - state estimator prognostics (used to track and smooth the features related to failure prediction), and 5 - physics-based prognostics (traditional approach that uses comprehensive modeling). SAE AIR5871 also outlines prognostic examples for a gas turbine blade failure mode (due to fatigue) and gas turbine performance degradation (due to fouling). Finally, SAE AIR5871 states that current research in prognostics is focused on improving the understanding of the physics of failure progression as well as the "logical and quantitative rationale for specifying prognostic system performance", which relies on the interaction between PHM providers and users [25].

\subsubsection{Energy Industry}

In 2013, the International Atomic Energy Agency (IAEA) produced a document (NP-T-3.14) focused on PHM for nuclear power plants [47]. More than 50 people (see pp. 135-136 of Ref. [47]) contributed to drafting and reviewing the final document. The document is comprehensive in its definitions and approaches for PHM of nuclear power plants. However, the background information and details for PHM measurement and analysis are applicable to other industrial processes and hence worthy of attention for PHM developers in other industries. 


\section{Current Standards Development}

New standards and revisions to existing standards related to PHM are currently under development. Table 2 categorizes these developing standards for manufacturing according to the general topics used throughout this document.

Table 2. Standards under development related to PHM for manufacturing.

\begin{tabular}{|c|c|c|c|c|c|c|c|c|c|c|c|}
\hline Organization & $\begin{array}{l}\text { Committee/ } \\
\text { Subcommittee }\end{array}$ & Standard & $\begin{array}{l}\text { 1st Edition } \\
\text { / Revision? }\end{array}$ & Title & $\frac{3}{3}$ & 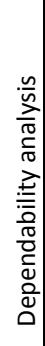 & 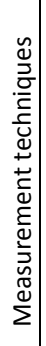 & 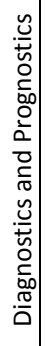 & 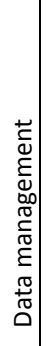 & 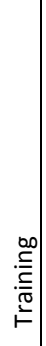 & 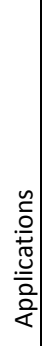 \\
\hline SAE & G-11r & ARP6204 & $1^{\text {st }}$ Edition & $\begin{array}{l}\text { Condition Based Maintenance } \quad \text { (CBM) } \\
\text { Recommended Practices }\end{array}$ & $x$ & & & & & & \\
\hline IEEE & RS & P1856 & $1^{\text {st }}$ Edition & $\begin{array}{l}\text { Standard Framework for Prognostics and Health } \\
\text { Management of Electronic Systems }\end{array}$ & $x$ & & & & & & \\
\hline ISO/IEC & JTC $1 /$ SC 7 & \begin{tabular}{|l|} 
ISO/IEC \\
$15909-3$ \\
\end{tabular} & $1^{\text {st }}$ Edition & $\begin{array}{l}\text { Software and system engineering - High-level } \\
\text { Petri nets - Part 3: Petri Net Extensions }\end{array}$ & & $\mathrm{x}$ & & & & & \\
\hline ISO & TC $108 / \mathrm{SC} 5$ & ISO 13379-2 & 1st Edition & $\begin{array}{l}\text { Condition monitoring and diagnostics of } \\
\text { machines - Data interpretation and diagnostics } \\
\text { techniques - Part 1: General guidelines }\end{array}$ & & & & $x$ & & & \\
\hline ISO & TC $108 / \mathrm{SC} 5$ & ISO 13381-1 & Revision & $\begin{array}{l}\text { Condition monitoring and diagnostics of } \\
\text { machines - Prognostics - Part 1: General } \\
\text { guidelines }\end{array}$ & & & & $\mathrm{x}$ & & & \\
\hline ISO & TC $108 / \mathrm{SC} 5$ & ISO 18129 & $1^{\text {st }}$ Edition & $\begin{array}{l}\text { Condition monitoring and diagnostics of } \\
\text { machines - Approaches for performance } \\
\text { diagnosis }\end{array}$ & & & & $\mathrm{x}$ & & & \\
\hline ISO & TC $184 / \mathrm{SC} 5$ & ISO $22400-1$ & $1^{\text {st }}$ Edition & $\begin{array}{l}\text { Manufacturing operations management - Key } \\
\text { performance indicators - Part 1: Overview, } \\
\text { concepts and terminology }\end{array}$ & & & & $\mathrm{x}$ & & & \\
\hline ISO & TC $184 / \mathrm{SC} 5$ & ISO $22400-2$ & $1^{\text {st }}$ Edition & $\begin{array}{l}\text { Manufacturing operations management - Key } \\
\text { performance indicators - Part 2: Definitions and } \\
\text { descriptions of KPIs }\end{array}$ & & & & $x$ & & & \\
\hline ISO & TC $184 / \mathrm{SC} 5$ & ISO 18435-3 & $1^{\text {st }}$ Edition & $\begin{array}{l}\text { Industrial automation systems and integration - } \\
\text { Diagnostics, capability assessment and } \\
\text { maintenance applications integration - Part 3: } \\
\text { Applications integration description method }\end{array}$ & & & & & $\mathrm{x}$ & & \\
\hline
\end{tabular}

The following sections provide additional details about these developing standards, organized according to the topics in Table 2.

\subsection{Overview}

Currently, SAE is developing SAE ARP6204, a standard for "Condition Based Maintenance (CBM) Recommended Practices," under the G-11r Reliability Committee [48]. The scope of the document is to outline a path for an organization to implement a CBM approach to maintenance, including practices regarding both CBM design and field equipment support [48]. The G-11r Reliability Committee has benchmarked the CBM framework and performance specifications and is developing a formal application specification [49]. 
Another broad standard under development by the Institute of Electrical and Electronics Engineers (IEEE) is IEEE P1856 - "Standard Framework for Prognostics and Health Management of Electronic Systems" [50]. In 2012, the IEEE Standards Board approved the new standard development project to produce IEEE P1856, which is sponsored by the Reliability Society (IEEE-RS) [51]. The working group meets regularly to prepare a draft for ballot in 2014 [51]. Even though this standard is being developed by IEEE, the intent is for it to have broad applicability in mechanical structures, civil structures, nuclear technology, and aeronautics [52].

\subsection{Dependability Analysis}

The first edition of ISO/IEC 15909-3 is under development by ISO/IEC JTC $1 /$ SC 7 to aid the use of highlevel Petri nets [53]. ISO/IEC 15909-3, expected to be the last part of the ISO/IEC 15909 series, will address the techniques for modularity and extensions of high-level Petri nets for dependability analysis of PHM systems.

\subsection{Diagnostics and Prognostics}

ISO 13379-2 ('Data-driven applications') will aid the condition monitoring of industrial machines via diagnostics and is currently in the committee draft stage within ISO/TC 108/SC 5. Also, ISO 13381-1 is now at the committee draft stage while being updated to advance prognostics within PHM systems. Furthermore, within the same subcommittee, a new standard, ISO 18129, is in the draft international stage to address 'approaches for performance diagnosis' [54].

Several standards are also being developed to guide the creation and measurements of key performance indicators (KPIs). KPIs are the most useful measures for monitoring and evaluating the performance of a production-oriented enterprise to help industries meet their performance targets in an intelligent manner [55]. KPIs are important for understanding and improving manufacturing plant performance in terms of waste elimination and goal achievement [56]. The most difficult plants to operate are network-structured plants with multiple products. KPIs are one of the potential support tools for continuous improvement of these challenging plant operations [55]. The set of KPIs at the highest levels should be used as target values for selecting the plant floor measures. The alignment of measurements and KPIs with the business operations is a partial reflection of the quality of the enterprise integration [55]. However, KPIs alone are not sufficient; warning and action limits are often necessary to help detect process trends, and information from industrial and control systems about process, equipment, operator, and materials can be effective as feedback for improving the productivity of manufacturing resources [56]. Hence, KPIs are serviced by effective PHM systems, so standards related to KPIs could easily influence the diagnostic and prognostic aspects of PHM systems.

ISO 22400 is a series of standards under development by ISO/TC 184/SC 5 to guide the creation, computation, measurement, utilization, and maturation of KPIs within the manufacturing operations management (MOM) domain [55]. The intent of the ISO 22400 series is to allow the broadest use of the $\mathrm{KPI}$ definition across the various industries and markets by factory managers, management software suppliers (e.g., involving PHM data management), engineers, and others involved in manufacturing.

The working draft (WD) of the first standard in the series, ISO/WD 22400-1, presents a framework for defining, composing, and utilizing KPIs for all types of industries (for batch, continuous, and discrete 
processes) based upon data from the process control domain (Levels 1-2 according to IEC 62264-1 [57]) for use in the MOM domain (Level 3) as well as the business domain (Level 4). ISO/WD 22400-1 is focused on internal processes (enterprise-to-plant processes) in contrast to external processes (including the life cycle process and product support). Specifically, ISO/WD 22400-1 defines the criteria for KPIs (a KPI should be 'aligned', 'quantifiable', 'actionable', etc.), the information it should contain ('name', 'description', 'formula', etc.), the types of KPIs ('ratio', 'utilization', 'rate', etc.), and the KPI model that includes its relationships and dependencies of KPIs on one another.

The working draft of the second standard in the series, ISO/WD 22400-2, defines the KPIs that reside at Level 3, the MOM domain, in contrast to KPIs that reside at Level 4, which are related to economic, business, logistic, and financial factors [56]. ISO/WD 22400-2 defines over $25 \mathrm{KPIs}$ that are currently in use and related to work units, such as 'worker efficiency', 'allocation ratio', and 'throughput rate.' Each $\mathrm{KPI}$ is based on the tabular structure set forth in ISO/WD 22400-1. The 'formula' for each KPI is a function of up to 30 various 'elements' or indicators related to time, logistics, quality, performance, and maintenance. Examples include actual production time (PT), scrap quantity (SQ), and upper specification limit (USL). Other KPIs, such as the overall equipment effectiveness (OEE) index (OEE Index = Availability $\times$ Effectiveness $\times$ Quality ratio), may be a function of other KPIs. For each KPI, ISO/WD 22400-2 shows the associated 'effect model diagram', which is a visual representation of how the KPI relates to the manufacturing process.

\subsection{Data Management}

Future improvements to ATA MSG-3 [10], used for developing maintenance plans for aircraft, engines, and systems, will involve an existing data format specification known as ATASPEC2000, a comprehensive set of e-Business specifications, products, and services that help to overcome the supply chain challenges in the aircraft industry [58]. ATA SPEC2000 helps aircraft manufacturers with information exchange in order to have statistically significant data for optimizing and developing maintenance programs.

\subsection{Professional Societies}

In addition to ISO, IEC, and other professional societies that help develop PHM standards, the PHM Society is now supporting the development of standards, methods, and metrics in PHM for the further development of PHM as an engineering discipline [2]. The PHM Society held their first standards panel at their 2012 conference in Minneapolis, Minnesota, USA. Invited speakers were from SAEB International, standards organizations, National Aeronautics and Space Administration (NASA), General Electric (GE), U.S. Army, NRG Energy, Penn State, and Georgia Tech. The need for PHM standards was identified due to various reasons, including the lack of standardized terms used in PHM, the lack of visibility, uniformity, and consistency of the PHM methods and tools, the need for compatibility and interoperability of PHM technology, and the needs for guidance in the practical use and development of PHM techniques [3]. 


\section{Summary and Conclusions}

The National Institute of Standards and Technology (NIST) conducted a survey of PHM-related standards to determine the industries and needs addressed by such standards, the extent of these standards, and any similarities as well as potential gaps among the documents. Over fifty (50) existing or developing standards from various national and international organizations were identified and summarized. This effort revealed that standards exist that are related to all aspects of the development of prognostics and health management systems: general overview, dependability analysis, measurement techniques, diagnostic analysis, prognostic analysis, data management, economics, performance metrics, and personnel training. Some standards were focused on providing guidance for specific applications, yet still broad enough for general application across industries. Other standards were more focused on a specific product or process within a target industry.

Based on the lessons learned from the PHM-related standards categorized according to topics in Table 1 and Table 2, recommendations can be made for the development of future PHM standards. It should be noted that the following suggestions are not necessarily comprehensive and are subject to change based on the changing needs and priorities of industry:

- The 'overview' standards are relatively thorough and therefore overlap significantly, but each provides important and unique guidance. The standards could be updated and harmonized by the respective organizations to provide better consolidation among the separate standards, providing for a more generally approved PHM process across disciplines.

- The 'dependability analysis' standards are thorough with respect to mathematical methodology, but could be extended to include treatments including economic and business influences. Perhaps the key performance indicator standards being developed for manufacturing could be combined with a dependability method to provide a bridge of guidance between design and business decisions.

- The 'measurement techniques' standards, being based in large part on the use of existing sensor technology, are not a hurdle for the development of PHM systems.

- The 'diagnostics and prognostics' standards are lacking, as previously stated, due in part to the difficult nature of reliable diagnostics and prognostics techniques across various industries. However, the existing standards are still valuable for industry. Collaborations among PHM experts are recommended for the generation of additional standards for diagnostics and prognostics.

- The 'data management' standards appear to be thorough and consistent among each other, providing generic structures for PHM data and control flow. Real-life test cases within manufacturing could be reported in future editions of these standards. 


\section{Acknowledgments}

The authors thank the American National Standards Institute (ANSI), on behalf of the International Organization for Standardization (ISO), and the United States Army for permission to reproduce information from their standards. Additionally, the authors thank the International Electrotechnical Commission (IEC) for permission to reproduce information from its International Standard IEC 60300-3-1 ed.2.0 (2003), IEC 60812 ed.2.0 (2006), IEC 61025 ed.2.0 (2006), IEC 61165 ed.2.0 (2006) and IEC 603003-3 ed.2.0 (2004). All such extracts are copyright of IEC, Geneva, Switzerland. All rights reserved. Further information on the IEC is available from www.iec.ch. IEC has no responsibility for the placement and context in which the extracts and contents are reproduced by the authors, nor is IEC in any way responsible for the other content or accuracy therein. 


\section{References}

[1] United States Army, "ADS-79C-HDBK - Aeronautical Design Standard Handbook for Condition Based Maintenance Systems for US Army Aircraft," ed, 2012.

[2] J. Bird and G. Shao, "A View of Standards for Prognostics and Health Management," International Journal of Prognostics and Health Management, 2013.

[3] Sony Mathew. (2012). PHM Standards - IEEE PHM Standard. Available: https://www.phmsociety.org/sites/phmsociety.org/files/PHM\%20Society\%20Standards\%20Res earch\%20Panel IEEE\%20PHM.pdf

[4] P. W. Kalgren, C. S. Byington, M. J. Roemer, and M. J. Watson, "Defining PHM, a lexical evolution of maintenance and logistics," in 2006 IEEE AUTOTESTCON - IEEE Systems Readiness Technology Conference, Anaheim, CA, United states, 2007, pp. 353-358.

[5] M. J. Roemer, J. Dzakowic, R. F. Orsagh, C. S. Byington, and G. Vachtsevanos, "Validation and verification of prognostic and health management technologies," in 2005 IEEE Aerospace Conference, Big Sky, MT, United states, 2005.

[6] S. B. Blaeser. (2012). The PHM Society's role as a member of the ANSI-Accredited US TAG to ISO/TC 108/SC 5 Condition monitoring and diagnostics of machine systems. Available: https://www.phmsociety.org/sites/phmsociety.org/files/ISO\%2OPHM\%20Society\%20presentati on.pdf

[7] International Organization for Standardization (ISO). (2013). ISO/TC 108/SC 5 Condition monitoring and diagnostics of machine systems. Available: http://www.iso.org/iso/home/standards development/list of iso technical committees/iso t echnical committee.htm?commid=51538

[8] International Organization for Standardization (ISO). (2013). ISO/TC 184 Automation systems and integration. Available: http://www.iso.org/iso/home/standards development/list of iso technical committees/iso t echnical committee.htm?commid=54110

[9] International Organization for Standardization (ISO), "ISO 17359:2011 - Condition monitoring and diagnostics of machines - General guidelines," ed, 2011.

[10] Air Transport Association of America, "MSG-3: Operator/Manufacturer Scheduled Maintenance Development, Volume 1 - Fixed Wing Aircraft," ed, 2013.

[11] C. Adams. (2009) Understanding MSG-3. Aviation Today. Available: http://www.aviationtoday.com/am/repairstations/Understanding-MSG-3 33062.html

[12] International Electrotechnical Commission, "IEC 60300-3-1 - Dependability management - Part 3-1: Application guide - Analysis techniques for dependability - Guide on methodology," ed, 2003.

[13] United States Department of Defense, "MIL-STD-1629A - Procedures for performing a failure mode, effects and criticality analysis," ed, 1980.

[14] International Electrotechnical Commission, "IEC 61703 - Mathematical expressions for reliability, availability, maintainability and maintenance support terms," ed, 2001.

[15] International Electrotechnical Commission, "IEC 60812 - Analysis techniques for system reliability - Procedure for failure mode and effects analysis (FMEA)," ed, 2006.

[16] SAE International, "ARP5580 - Recommended Failure Modes and Effects Analysis (FMEA) Practices for Non-Automobile Applications," ed, 2001.

[17] SAE International, "J1739 - Potential Failure Mode and Effects Analysis in Design (Design FMEA), Potential Failure Mode and Effects Analysis in Manufacturing and Assembly Processes (Process FMEA)," ed, 2009. 
[18] International Electrotechnical Commission, "IEC 61025 - Fault tree analysis (FTA)," ed, 2006.

[19] International Electrotechnical Commission, "IEC 61165 - Application of Markov techniques," ed, 2006.

[20] International Organization for Standardization (ISO) and International Electrotechnical Commission (IEC), "ISO/IEC 15909-1:2004 - Software and system engineering - High-level Petri nets - Part 1: Concepts, definitions and graphical notation," ed, 2004.

[21] J. K. Truss, Discrete Mathematics for Computer Scientists, 2nd ed.: Addison-Wesley, 1998.

[22] International Organization for Standardization (ISO) and International Electrotechnical Commission (IEC), "ISO/IEC 15909-2:2011 - Software and system engineering - High-level Petri nets - Part 2: Transfer format," ed, 2011.

[23] International Electrotechnical Commission, "IEC 60300-3-3 - Dependability management - Part 3-3: Application guide - Life cycle costing," ed, 2004.

[24] International Organization for Standardization (ISO), "ISO 13379-1:2012 - Condition monitoring and diagnostics of machines - Data interpretation and diagnostics techniques - Part 1: General guidelines," ed, 2012.

[25] SAE International, "AIR5871 - Prognostics for Gas Turbine Engines," ed, 2008.

[26] International Organization for Standardization (ISO), "ISO 13381-1:2004 - Condition monitoring and diagnostics of machines - Prognostics - Part 1: General guidelines," ed, 2004.

[27] International Organization for Standardization (ISO), "ISO 13372:2012 - Condition monitoring and diagnostics of machines - Vocabulary," ed, 2012.

[28] International Organization for Standardization (ISO), "ISO 13374-1:2003 - Condition monitoring and diagnostics of machines - Data processing, communication and presentation - Part 1 : General guidelines," ed, 2003.

[29] MIMOSA. (2006). MIMOSA's Open System Architecture for Enterprise Application Integration (OSA-EAl) Technical Architecture Summary Available: http://www.mimosa.org/sites/default/files/TechDocs/OSA-

EAl Technical Architecture Summary Dec 2006.pdf

[30] International Organization for Standardization (ISO), "ISO 13374-2:2007 - Condition monitoring and diagnostics of machines - Data processing, communication and presentation - Part 2: Data processing," ed, 2007.

[31] MIMOSA. (2013). MIMOSA's Open System Architecture for Enterprise Application Integration (OSA-EAI). Available: http://www.mimosa.org/?q=node/300

[32] C. S. Byington, M. J. Roemer, G. J. Kacprzymki, and T. Galie, "Prognostic enhancements to diagnostic systems for improved condition-based maintenance," in 2002 IEEE Aerospace Conference, Big Sky, MT, United states, 2002, pp. 2815-2824.

[33] C. Staller, "Condition Based Maintenance - What is the condition of Condition Based Maintenance?," ed. MIMOSA, 2013.

[34] MIMOSA, "Condition Based Operations for Manufacturing," ed, 2004.

[35] International Organization for Standardization (ISO), "ISO 13374-3:2012 - Condition monitoring and diagnostics of machines - Data processing, communication and presentation - Part 3: Communication," ed, 2012.

[36] International Organization for Standardization (ISO), "ISO 15926-1:2004 - Industrial automation systems and integration - Integration of life-cycle data for process plants including oil and gas production facilities - Part 1: Overview and fundamental principles," ed, 2004.

[37] International Organization for Standardization (ISO), "ISO 10303-11:2004 - Industrial automation systems and integration - Product data representation and exchange - Part 11: Description methods: The EXPRESS language reference manual," ed, 2004. 
[38] International Organization for Standardization (ISO), "ISO 15926-2:2003 - Industrial automation systems and integration - Integration of life-cycle data for process plants including oil and gas production facilities - Part 2: Data model," ed, 2003.

[39] International Organization for Standardization (ISO), "ISO 18435-1:2009 - Industrial automation systems and integration - Diagnostics, capability assessment and maintenance applications integration - Part 1: Overview and general requirements," ed, 2009.

[40] International Organization for Standardization (ISO), "ISO 18435-2:2012 - Industrial automation systems and integration - Diagnostics, capability assessment and maintenance applications integration - Part 2: Descriptions and definitions of application domain matrix elements," ed, 2012.

[41] IEEE Standards Association, "1232-2010 - IEEE Standard for Artificial Intelligence Exchange and Service Tie to All Test Environments (AI-ESTATE)," ed, 2010.

[42] International Organization for Standardization (ISO), "ISO 15531-44:2010 - Industrial automation systems and integration - Industrial manufacturing management data -Part 44: Information modelling for shop floor data acquisition," ed, 2010.

[43] International Organization for Standardization (ISO), "ISO 18436-1:2012 - Condition monitoring and diagnostics of machines - Requirements for qualification and assessment of personnel Part 1: Requirements for assessment bodies and the assessment process," ed, 2012.

[44] SAE Digital Library. (2013). SAE Aerospace Standards (AS). Available: http://www.saedigitallibrary.org/content/standards/sae-aerospace-standards/

[45] SAE International, "ARP1587B - Aircraft Gas Turbine Engine Health Management System Guide," ed, 2007.

[46] SAE International. (2013). Aircraft Gas Turbine Engine Health Management System Guide. Available: http://standards.sae.org/arp1587b/

[47] International Atomic Energy Agency (IAEA), "NP-T-3.14 - Advanced Surveillance, Diagnostic and Prognostic Techniques in Monitoring Structures, Systems and Components in Nuclear Power Plants," 2013.

[48] SAE International. (2013). Condition Based Maintenance (CBM) Recommended Practices. Available: http://standards.sae.org/wip/arp6204/

[49] Y. Zhou, J. Bo, and T. Wei, "A review of current prognostics and health management system related standards," Chemical Engineering Transactions, vol. 33, pp. 277-282, 2013.

[50] IEEE Standards Association. (2013). P1856 - Standard Framework for Prognostics and Health Management of Electronic Systems. Available: http://standards.ieee.org/develop/project/1856.html

[51] IEEE Reliability Society. (2014). IEEE Standards Development. Available: http://rs.ieee.org/ieeestandards-development.html

[52] The Center for Advanced Life Cycle Engineering (CALCE). (2013). CALCE PHM News - August 2013. Available: http://www.prognostics.umd.edu/WhatsNew/2013/calce-phm-aug2013.html

[53] International Organization for Standardization (ISO) and International Electrotechnical Commission (IEC), "ISO/IEC CD 15909-3 - Software and system engineering - High-level Petri nets - Part 3: Petri Net Extensions," ed, 2014.

[54] International Organization for Standardization (ISO), "ISO/DIS 18129 - Condition monitoring and diagnostics of machines - Approaches for performance diagnosis," ed, 2014.

[55] International Organization for Standardization (ISO), "ISO/WD 22400-1 - Manufacturing operations management - Key performance indicators - Part 1: Overview, concepts and terminology," ed, 2013. 
[56] International Organization for Standardization (ISO), "ISO/WD 22400-2 - Manufacturing operations management - Key performance indicators - Part 2: Definitions and descriptions of KPIs," ed, 2013.

[57] International Electrotechnical Commission, "IEC 62264-1 - Enterprise-control system integration - Part 1: Models and terminology," ed, 2003.

[58] Air Transport Association of America. (2012). SPEC2000. Available: http://www.spec2000.com/ 